\author{
UNIVERSIDADE DE SÃO PAULO \\ ESCOLA DE ARTES, CIÊNCIAS E HUMANIDADES \\ PROGRAMA DE PÓS-GRADUAÇÃO EM SISTEMAS DE INFORMAÇÃO
}

BIANCA CANEZIM LETTI

Arquitetura para representação e processamento de dados para apoio a gestão de equipes de saúde

São Paulo

2020 


\section{Arquitetura para representação e processamento de dados para apoio a} gestão de equipes de saúde

Dissertação apresentada à Escola de Artes, Ciências e Humanidades da Universidade de São Paulo para obtenção do título de Mestre em Ciências pelo Programa de Pós-graduação em Sistemas de Informação.

Área de concentração: Metodologia e Técnicas da Computação

Versão corrigida contendo as alterações solicitadas pela comissão julgadora em 27 de Abril de 2020. A versão original encontra-se em acervo reservado na Biblioteca da EACH-USP e na Biblioteca Digital de Teses e Dissertações da USP (BDTD), de acordo com a Resolução CoPGr 6018, de 13 de outubro de 2011.

Orientador: Prof. Dr. Luciano Vieira de Araújo

São Paulo 
Autorizo a reprodução e divulgação total ou parcial deste trabalho, por qualquer meio convencional ou eletrônico, para fins de estudo e pesquisa, desde que citada a fonte.

CATALOGAÇÃO-NA-PUBLICAÇÃO

(Universidade de São Paulo. Escola de Artes, Ciências e Humanidades. Biblioteca) CRB 8 - 4936

Letti, Bianca Canezim

Arquitetura para representação e processamento de dados para apoio a gestão de equipes de saúde / Bianca Canezim Letti ; orientador, Luciano Vieira de Araújo. - 2020.

$71 \mathrm{f}$ : : il

Dissertação (Mestrado em Ciências) - Programa de PósGraduação em Sistemas de Informação, Escola de Artes, Ciências e Humanidades, Universidade de São Paulo. Versão corrigida

1. Metodologia e técnicas de computação. 2. Computação aplicada. 3. Gestão da informação. 4. Saúde. I. Araújo, Luciano Vieira de, orient. II. Título

$$
\text { CDD 22. ed. - } 005.1
$$


Dissertação de autoria de Bianca Canezim Letti, sob o título "Arquitetura para representação e processamento de dados para apoio a gestão de equipes de saúde", apresentada à Escola de Artes, Ciências e Humanidades da Universidade de São Paulo, para obtenção do título de Mestre em Ciências pelo Programa de Pós-graduação em Sistemas de Informação, na área de concentração Metodologia e Técnicas da Computação, aprovada em 27 de Abril de 2020 pela comissão julgadora constituída pelos doutores:

Prof. Dr. Luciano Vieira de Araújo

Universidade de São Paulo - EACH, Escola de Artes, Ciências e Humanidades Presidente

Prof. Dr. Carlos Bandeira de Mello Monteiro

Universidade de São Paulo - EACH, Escola de Artes, Ciências e Humanidades

Prof. Dr. Marcelo Medeiros Eler

Universidade de São Paulo - EACH, Escola de Artes, Ciências e Humanidades

Prof. Dr. Ivan Torres Pisa

Universidade Federal de São Paulo - Departamento de informática em saúde 
Aos meus pais que, com muito suor, sempre priorizaram a minha educação e me deram força para continuar nos momentos mais difíceis, que me ensinaram que não existe caminho fácil, e que o mais importante da vida é fazer aquilo que se ama com garra e determinação, pois quando fazemos aquilo que amamos, faremos até o último dia da vida. Ao meu orientador Luciano, por todos os ensinamentos, por me apoiar e guiar sempre pelos caminhos corretos e por tornar a profissão de professor uma das minhas maiores admirações. 


\section{Agradecimentos}

Primeiramente, a Escola de Artes, Ciências e Humanidades da Universidade de São Paulo, por ter sempre proporcionado um ambiente de inovação e multidisciplinaridade que me fez explorar outras áreas de pesquisa, para elaboração deste projeto, e estabelecer a minha paixão pela área de mobile health applications.

A Lara Miguel Quirino Araújo por todos os ensinamentos de medicina e saúde, por solucionar as dúvidas em relação ao contexto médico, segunda opinião médica e as demais necessidades durante todo o projeto de pesquisa.

A Doutora Cassilda da Universidade Federal de Goiás por prover a simulação de dados de pacientes para que pudéssemos compreender o contexto médico atual, simulando a realidade e tornando esta pesquisa mais rica em sua contribuição para a comunidade científica. 
"Tudo o que um sonho precisa para ser realizado é alguém que acredite que ele possa ser realizado." 


\section{Resumo}

LETTI, Bianca Canezim. Arquitetura para representação e processamento de dados para apoio a gestão de equipes de saúde. 2020. 71 f. Dissertação (Mestrado em Ciências) - Escola de Artes, Ciências e Humanidades, Universidade de São Paulo, São Paulo, 2020.

O uso de smartphones na área médica é frequente e tem se tornado cada vez mais comum a utilização de aplicativos de mensagem instantânea para que os médicos se comuniquem e possam dar segundas opiniões a fim de apoiar o tratamento dos pacientes. No entanto, essas aplicações não estão preparadas e estruturadas para apoiar adequadamente o ambiente no qual trabalham e as respectivas equipes de saúde. Mensagens podem ser enviadas indevidamente para pessoas ou grupos, ou mesmo mensagens importantes podem não ser percebidas em uma grande quantidade de conversas nos aplicativos. Nesse contexto, uma arquitetura capaz de representar e apoiar a comunicação de forma a facilitar a gestão e organização da informação pode auxiliar na redução das limitações identificadas. Essa pesquisa propôs uma abordagem para os desafios de identificação e extração das informações de conversas caracterizadas por dados não estruturados e transformação dessas informações em dados semiestruturados, por meio da proposição dessa arquitetura. Como contribuições, promoveu o auxílio da comunicação entre médicos e equipe de saúde através do desenvolvimento de um aplicativo, propôs uma arquitetura modular multi etapas e conseguiu contribuir com a gestão da informação por meio da organização e apresentação dos dados semiestruturados, apoiando a segunda opinião médica, a tomada de decisões e acompanhamento do tratamento dos pacientes.

Palavras-chaves: Mensagens Instantâneas. Arquitetura. Segunda Opinião Médica. Gestão da informação. Textos semiestruturados. 


\begin{abstract}
LETTI, Bianca Canezim. Data representation and processing architecture to support healthcare team management. 2020. 71 p. Dissertation (Master of Science) - School of Arts, Sciences and Humanities, University of São Paulo, São Paulo, 2020.

The use of smartphones in the medical field is frequent and it has become increasingly common to use instant messaging applications so that doctors can communicate and can give second opinions in order to support the treatment of patients. However, these applications are not prepared and structured to adequately support the environment in which they work and the respective health teams. Messages can be sent improperly to people or groups or even important messages may not be noticed in a large amount of conversations in the applications. In this context, an architecture capable of representing and supporting communication in order to facilitate the information management and organization can assist in reducing the identified limitations. This research proposed an approach to the challenges of identifying and extracting information from conversations characterized by unstructured data and transforming that information into semi-structured data through the proposition of this architecture. As contributions, it promoted the aid of communication between physicians and the health team through the development of an application, proposed a modular multi-stage architecture and managed to contribute to information management through the organization and presentation of semi-structured data, supporting the second medical opinion, decision-making and monitoring the treatment of patients.
\end{abstract}

Keywords: Instant Messages. Architecture. Second Medical Opinion. Healthcare Management. Semi-structured text. 


\section{Lista de figuras}

Figura 1 - Operações de pré-processamento de textos adaptado e traduzido de (S.VIJAYARANI; JANANI, 2016) . . . . . . . . . . . . . 25

Figura 2 - Texto sem passar pelo processo de tokenização adaptado de (INGERSOLL; MORTON; FARRIS, 2013) . . . . . . . . . . . . 27

Figura 3 - Texto tokenizado adaptado de (INGERSOLL; MORTON; FARRIS, 2013) 27

Figura 4 - Representação da técnica de stemming adaptada de (FILHO, 2016) . 29

Figura 5 - Representação da técnica de stemming em um texto adaptada de (HONORATO et al., 2004) . . . . . . . . . . . . . . . . . . 29

Figura 6 - Representação da técnica de remoção de stop words em um texto adaptada de (HONORATO et al., 2004) . . . . . . . . . . . 30

Figura 7 - Representação das tecnologias usadas no processo de validação . . . . . 33

Figura 8 - Exemplo de dinâmica de interação humana entre médicos e equipe médica sobre pacientes e exames . . . . . . . . . . . 36

Figura 9 - Processo da arquitetura . . . . . . . . . . . . 38

Figura 10 - Processo da arquitetura detalhado . . . . . . . . . . . . . . . . . 39

Figura 11 - Processo de troca de mensagens detalhado . . . . . . . . . . . . . . . . 40

Figura 12 - Processo detalhado do quadrante dois da arquitetura sobre transformação 41

Figura 13 - Processo detalhado do quadrante dois da arquitetura sobre semiestruturação de dados . . . . . . . . . . . . . . . . . . . . . . 4 45

Figura 14 - Representação da semiestruturação da conversação ........46

Figura 15 - Diagrama de uso da troca de mensagens entre médico e o sistema e a etapa final de visualização dos dados do paciente de forma organizada. 50

Figura 16 - Validação arquitetura de entrada e saída - Login . . . . . . . . . . . . . 51

Figura 17 - Validação arquitetura de entrada e saída - Médicos . . . . . . . . . . . 51

Figura 18 - Validação arquitetura de entrada e saída - Chats . . . . . . . . . . . 52

Figura 19 - Interação entre médicos com dados simulados no healthMessage - Parte 153

Figura 20 - Interação entre médicos com dados simulados no healthMessage - Parte 254

Figura 21 - Interação entre médicos com dados simulados no healthMessage - Parte 355

Figura 22 - Processamento no servidor . . . . . . . . . . . . . 56 
Figura 23 - Demonstração de API node que realiza o envio de uma mensagem entre frontend e o servidor . . . . . . . . . . . . . 5 56

Figura 24 - Demonstração de trecho de código do servidor que é responsável pelo relacionamento com o banco de dados não relacional . . . . . . . . . . 57

Figura 25 - Fluxograma de processo linear que representa o processamento de transformação dentro do servidor . . . . . . . . . . . . . . 57

Figura 26 - Sugestão de palavras baseadas no cálculo de frequência de termos . . . 58

Figura 27 - Representação da semiestruturação da conversação - jSON de saída . . 59

Figura 28 - Processamento de visualização das informações organizadas . . . . . . 60

Figura 29 - Representação do processo de saída do contexto simulado após semiestruturação e organização . . . . . . . . . . . . . . . . . . . . . . 60 60

Figura 30 - Representação do processo de saída do contexto simulado após semiestruturação e organização - Outros exames (exames de sangue) . . . . . 61 


\section{Lista de quadros}

Quadro 1 - Exemplo de dados simulados conversados entre médicos em aplicativos de mensageria instantânea . . . . . . . . . . . . . . . . . . . . . . . . 49 
Lista de abreviaturas e siglas

m-Health Mobile Health Applications

UTI Unidades de terapia intensiva

uHealth Ubiquitous technology healthcare services

API Application Programming Interface 


\section{Sumário}

Introdução . . . . . . . . . . . . . . . . 15

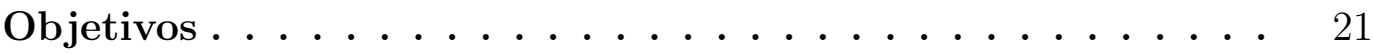

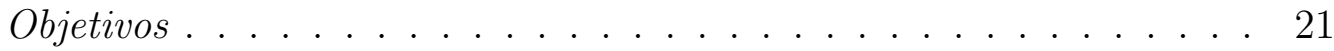

Fundamentação Teórica . . . . . . . . . . . . . 22

(5) Etapa de organização . 44 
6.4 Processo de Apresentação e Aprendizado . . . . . . . . . . . . . . 47

7

Validação . . . . . . . . . . . . . . . . . . 48

7.1 Módulo da arquitetura de entrada e saída . . . . . . . . . . . . . . . . 49

7.2 Módulo da arquitetura do servidor . . . . . . . . . . . . 55

7.3 Módulo de transformação dos dados . . . . . . . . . . . . . . . 57

7.3.1 Frequência de Palavras . . . . . . . . . . . . . . . 58

7.3.2 Módulo de semiestruturação e organização . . . . . . . . . . . . 58

7.3.3 Módulo de saída (visualização das informações organizadas) . . . 59

8

Discussão . . . . . . . . . . . . . . . . 62

8.1

Trabalhos futuros

64

9

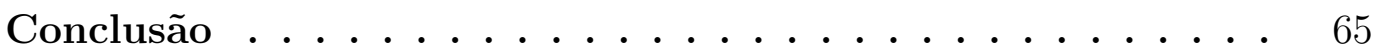

Referências $^{1} \ldots \ldots \ldots \ldots 6$

$\overline{1}$ De acordo com a Associação Brasileira de Normas Técnicas. NBR 6023. 


\section{Introdução}

Celulares passaram a ser computadores portáteis, definidos como smartphones, esses dispositivos podem performar várias tarefas semelhantes às de um computador pessoal e estão equipados com um sistema operacional potente que possui características multitarefas, que possibilitam o acesso a diversas aplicações, denominadas "apps" e que, por sua vez, dão acesso à diversas funcionalidades, como assistir a filmes ou ouvir músicas (PARK; LEE, 2011; ANSHARI et al., 2017).

A adoção desses dispositivos mudou também o hábito das pessoas que os utilizam: as pessoas socializam de novas formas, fazem tarefas de novos modos, e até compartilham informações de novas maneiras (OULASVIRTA et al., 2011).

As tecnologias relacionadas à smartphones são poderosas e as diversas funcionalidades oferecidas por estes dispositivos podem ser aplicadas em vários domínios. Neste contexto, de acordo com Han e Yi (2018), o uso destas funcionalidades pode ser assimilado em diferentes perspectivas da vida, incluindo a comunicação.

De acordo com uma pesquisa realizada pela GSMA (2020) (Global System for Mobile Communications Association), em seu relatório anual sobre a economia para dispositivos móveis, o relatório demonstra que aproximadamente 5,2 bilhões de pessoas haviam se inscrito em serviços para dispositivos móveis até o final de 2019, representando $67 \%$ da população global e, apesar de estar mais difícil ver esse crescimento pela saturação de dispositivos pelo mundo, ainda é possível vê-lo acontecer. A previsão é que até 2025 esse número aumente para 5,8 bilhões, representando cerca de $70 \%$ da população mundial.

Com a popularização dos celulares, o investimento nas tecnologias para dispositivos móveis vem avançando rapidamente, em uma crescente constante e com um custo relativamente baixo, perto do potencial de impacto que podem gerar. Atingindo largas populações, as tecnologias desenvolvidas para interação humana, por meio de mensagens de texto, por exemplo, proporcionam comunicação em larga escala em tempo real (FREE et al., 2013).

O uso de smartphones teve impacto em diferentes áreas, incluindo a área da saúde. Boulos et al. (2014) em seu estudo, traz que a comunicação em tempo real, sob demanda em dispositivos de alta capacidade também revolucionaram a forma como nos comunicamos em nosso dia a dia. Com a rápida popularização destes dispositivos associada à disseminação 
da internet, os smartphones trouxeram também uma solução de acessibilidade e maior qualidade para a área da saúde (WU et al., 2019).

Dentro da área da saúde, o uso de aplicativos, nesse contexto, tem a denominação de mobile health applications ou como é popularmente conhecido "m-health". Um m-health pode ser globalmente definido como a prática médica suportada por dispositivos móveis, como celulares, dispositivos de monitoração ao paciente, assistentes digitais pessoais ou outros dispositivos conectados à internet (HEERDEN; TOMLINSON; SWARTZ, 2012).

Em relação ao uso de $m$-healths, existem diversas aplicações preparadas para atender aos pacientes. Subhi et al. (2015) conduz uma revisão sistemática na qual avalia 6520 aplicativos disponíveis nas principais lojas de aplicativos (Google Play e Apple App Store). Esse estudo analisa as aplicações encontradas, demonstrando que são majoritariamente voltadas para os pacientes. Já para o contexto de aplicativos para médicos, Payne, Wharrad e Watts (2012) conduzem uma pesquisa no Reino Unido, que demonstra que, quando há aplicativos disponíveis para médicos, esses são utilizados, em sua maioria, para fins educacionais.

O ambiente médico é complexo, dinâmico e requer comunicação em tempo real para apoiar a segunda opinião médica.

A origem sobre o termo segunda opinião médica remete ao passado, quando ainda eram realizados programas para apoio a segunda opinião. Ruchlin, Finkel e McCarthy (1982), em sua pesquisa, explicam sobre o principal objetivo desses programas na época, que era prover ao paciente informações adicionais em relação à necessidade para cirurgias e, quando necessário, modos alternativos de tratamento.

A segunda opinião médica pode ser definida como uma prática na qual uma segunda ou mais opiniões são fornecidas, formuladas, reformuladas e, finalmente, levadas a uma estratégia de tratamento significativa (ABDULLA, 2015).

Morsch (2019) realizou uma pesquisa que apresenta um levantamento realizado com 150 médicos de Juiz de Fora/MG, revelando que 79\% dos médicos estimulam seus pacientes a buscar a avaliação de colegas, especialmente quando o prognóstico é restrito ou há mais de uma possibilidade terapêutica.

Nesse contexto, orientados pela necessidade de comunicação constante, o uso de smartphones tem sido bastante significativo no contexto médico. Médicos e a equipe médica vêm utilizando aplicativos de mensageria instantânea como o WhatsApp para estabelecer 
a comunicação clínica necessária na área da saúde no dia a dia de trabalho (WANI et al., 2013; J.JOHNSTON et al., 2015; GULACTI et al., 2016).

O WhatsApp Messenger é uma aplicação de troca de mensagens em tempo real, e facilita que usuários de smartphones enviem mensagens de texto e outros tipos de arquivos de mídia (como fotos, vídeos e mensagens de voz) para seus contatos (GULACTI et al., 2016).

O conceito de mensagens instantâneas, por sua vez, se refere à troca de mensagens entre usuários, em tempo real (SODERLAND, 1999).

Uma pesquisa conduzida por Gulacti et al. (2016), considera o WhatsApp útil como uma ferramenta de comunicação entre médicos, especialmente para necessidades de emergência quando eles estão fora do hospital.

O uso do WhatsApp em várias regiões do mundo e, particularmente em áreas rurais e países subdesenvolvidos, demonstrou facilitar a comunicação entre os profissionais de saúde em termos de identificação mais rápida de problemas e gerenciamento de doenças agudas imediatas. Além disso, estudos recentes demonstraram que o aumento da presença do WhatsApp na medicina, em vários outros campos específicos, reflete uma aceitação do seu uso, e é um sistema promissor quando usado como uma ferramenta de comunicação entre médicos. No entanto outras pesquisas nesse sentido ainda precisam ser realizadas a fim de categorizar o WhatsApp como uma ferramenta de telemedicina (GIORDANO et al., 2017).

De acordo com pesquisa conduzida por Boulos, Giustini e Wheeler (2016), compartilhar textos, documentos e imagens no WhatsApp pode ter um papel na melhora do processo de tomada de decisão e tratamento ao paciente, desde consultas até o leito do paciente. A ferramenta facilita e melhora a comunicação para as equipes de saúde, oferecendo formas para os médicos monitorarem o trabalho realizado pela equipe clínica. Adicionar o WhatsApp como ferramenta de comunicação clínica facilita os tempos de resposta entre as equipes de saúde, passagens de turno mais rápidas para residentes em hospitais e a disseminação de mensagens de saúde pública para mais pessoas, no entanto, mais pesquisas para resolver preocupações relacionadas à confidencialidade e à comunicação segura precisam ser realizadas.

Também é importante demonstrar como o uso dos smartphones na área médica se dá em outros lugares que não somente os países desenvolvidos. 
Na Nigéria também há indicações do uso de smartphones no ambiente hospitalar. Na pesquisa conduzida por Yahya (2019), em Kaduna, mostrou que a maior razão para os médicos utilizarem smartphones se dá para verificar detalhes sobre determinada condição de doenças, praticamente $50 \%$ dos respondentes reportaram usar os telefones intensamente para essa atividade. Além disso, 46,8\% dos respondentes também usaram os telefones para fazer ligações ou enviar mensagens para os colegas de trabalho, verificar diagnósticos diferentes de determinadas doenças $(42,9 \%)$ ou para a parte de medicamentos, sendo 42,5\% para verificar as indicações de medicamentos, 42,9\% as interações entre medicamentos e 41,9\% para o uso de medicamentos em circunstâncias especiais. Como conclusão da pesquisa, os autores trazem que o uso de smartphones em Kaduna na Nigéria, por médicos é universal e usada de forma extensiva para se comunicar com os colegas e realizar outras tarefas. Apesar da maior parte dos médicos acharem o uso dos smartphones bastante útil, muitos médicos também estavam insatisfeitos com o nível de uso, por razões de restrições de tempo e disponibilidade de conexão de internet confiável, o que poderia ser remediado com o desenvolvimento de aplicativos dedicados e com curadoria de conteúdo para manter informações precisas e confiáveis.

No Brasil, uma pesquisa conduzida por Ladaga et al. (2018) realizou uma revisão sistemática da literatura nacional e internacional e teve como objetivo avaliar a importância do uso do WhatsApp na área da saúde. Como resultado, a pesquisa relatou que dos 64 trabalhos analisados, 24 utilizaram o aplicativo na prática interna entre médicos e equipe de saúde e sete trabalhavam com intervenção de saúde à distância, reforçando um aumento no número de pesquisas científicas relacionadas ao uso do WhatsApp no âmbito da saúde. Também é discutido o uso do WhatsApp como prática interna e conclui-se que é uma ferramenta benéfica para a promoção da saúde e nas relações entre profissionais da saúde e pacientes.

De acordo com uma pesquisa conduzida por Nascimento et al. (2020), que realiza um estudo sobre o uso de serviços de mensageria instantânea, por meio de smartphones na prática médica no Brasil, 97\% dos respondentes classificados entre residentes, estudantes e especialistas declararam que estão usando aplicativos relacionados à troca de mensagens instantâneas para fins médicos. De acordo com a percepção desses respondentes, os autores identificaram que não houve diferenças significativas entre os grupos de médicos entrevistados e cerca de 76,2\% já usaram essas aplicações para compartilhar exames de imagens, testes de laboratório ou prontuários médicos de pacientes. Adicionalmente, a 
maioria dos participantes pertencia a grupos fechados do estudo de caso clínico (90,5\%), e frequentemente, a mais de três grupos.

Na pesquisa, ainda é possível analisar uma tabela com os respondentes em relação a várias perguntas. $97 \%$ dos respondentes utilizam o WhatsApp para as atividades mencionadas, $13,9 \%$ o Telegram e 8,2\% o iMessage. Além das ferramentas utilizadas, também é possível compreender sobre a frequência de discussões em tempo real para casos clínicos, na qual cerca de 18,6\% dos respondentes realizam essas discussões diariamente e 41,1\% semanalmente. A conclusão desse estudo demonstra que os aplicativos de mensagens instantâneas se tornaram populares entre médicos e estudantes de medicina, inclusive no Brasil. No entanto, ao mesmo tempo, demonstrou quão pouco médicos e estudantes de medicina sabem sobre as implicações legais do uso dessas ferramentas, aconselhando que a legislação reguladora seja antecipada. Além disso, os autores sugerem que procedimentos operacionais inovadores devem ser propostos para garantir a segurança de todas as partes envolvidas e entendem que isso se faz necessário, principalmente em países em desenvolvimento, como o Brasil, no qual as regulamentações sobre esse assunto permanecem escassas (NASCIMENTO et al., 2020).

De acordo com os resultados das pesquisas encontradas para o estudo proposto, identificou-se que os aplicativos de troca de mensagens instantâneas não apresentam recursos para um apoio amplo, além do envio de mensagens e arquivos, atividades de uma equipe de saúde. Por exemplo, mensagens podem ser enviadas indevidamente para pessoas e grupos. Ou mesmo mensagens urgentes podem não serem percebidas em meio a uma grande quantidade de conversas em curso nos aplicativos. Este trabalho propõe uma abordagem que auxilia na redução dessas limitações ao propor uma arquitetura para organizar mensagens trocadas entre equipes de saúde.

O trabalho de pesquisa a seguir está estruturado nas seguintes seções: o capítulo 2 apresenta a motivação que originou este trabalho; o capítulo 3 faz referência aos objetivos que guiaram este trabalho de pesquisa; o capítulo 4 descreve a fundamentação teórica que embasa fundamentalmente essa pesquisa; o capítulo 5 discorre sobre os materiais e métodos utilizados para realização desse trabalho; o capítulo 6 explica sobre a arquitetura proposta neste trabalho de pesquisa; o capítulo 7 representa como a arquitetura proposta nesse projeto de pesquisa foi validada; o capítulo 8 apresenta a discussão final desse trabalho; o capítulo 9 descreve as considerações finais e por fim, a seção 9 também apresenta as referências bibliográficas utilizadas para realização deste trabalho de pesquisa. 


\section{Motivação}

O ambiente médico é amplo e composto por diferentes profissionais e requer comunicação ágil entre membros da equipe. Ao longo das atividades, médicos e equipe preenchem prontuários, realizam exames de pacientes, indicam medicações, encaminham pacientes a outros médicos, pedem e necessitam de segundas opiniões médicas, dentre tantas outras atividades. Todas essas tarefas requerem comunicação em tempo real. Além do mais, o trabalho não termina ao deixar o ambiente hospitalar, muitas vezes a equipe necessita se comunicar para tirar dúvidas e atualizar informações sobre o acompanhamento de pacientes. Esse cenário apresenta a necessidade de utilização de ferramentas de apoio à comunicação. Esse tipo de comunicação tem evoluído junto com o avanço tecnológico, sendo apoiada por dispositivos como telefones, pagers/bips e, recentemente, por smartphones e seus aplicativos.

Atualmente, com o uso de aplicativos para comunicação, os médicos conseguem compartilhar pedidos e resultados de exames, prontuários, quadros clínicos, atualizações sobre quadros graves de pacientes, conversar e opinar sobre o tratamento de determinado paciente e até acompanhar a evolução sobre o tratamento de um paciente.

As aplicações de mensageria instantânea, na contemporaneidade, proporcionam conversas em tempo real entre grupos ou entre indivíduos, mas não estão preparadas e não possuem recursos estruturados para o contexto médico de atuação e para apoio à comunicação entre equipes médicas, podendo contribuir para dificultar a busca de informações necessárias para prontuários, tendo potencial para induzir a erros médicos e também comprometer o tratamento dos pacientes.

Nessa perspectiva, uma arquitetura para representar e apoiar a comunicação entre médicos e suas equipes, colaborando com a gestão e organização da informação e troca de mensagens se faz necessária. 


\section{Objetivos}

\subsection{Objetivos}

O objetivo deste trabalho é propor e implementar uma arquitetura computacional para representação e análise de mensagens instantâneas não estruturadas, que apoie o acompanhamento de atividades relacionadas aos tratamentos e cuidados oferecidos por equipes médicas.

\subsection{Objetivos especificos}

Este trabalho possui os seguintes objetivos específicos:

- Realizar levantamento bibliográfico relacionado ao contexto das aplicações de mHealth disponíveis atualmente;

- Definir uma arquitetura computacional para identificação de informações a serem acompanhadas durante o tratamento;

- Definir uma representação para armazenamento e análise das mensagens trocadas;

- Propor formatos de visualização das informações identificadas;

- Implementar um aplicativo para validação da interface proposta; 


\section{Fundamentação Teórica}

\subsection{Dados não estruturados}

Os dados podem ser apresentados ou armazenados em diversos formatos. A representação escolhida para dados indica a presença ou ausência de disposição prévia para organizar os dados. Como consequência, a forma escolhida para seu armazenamento impacta diretamente em seu processamento, pois, caso os dados atendam a uma determinada organização, ela poderá ser utilizada para sua recuperação e processamento.

A forma mais simples de representação dos dados é a não estruturada. Ou seja, não existe uma regra de representação dos dados que os organize e que permita sua recuperação. A identificação de um dado específico ou de um conteúdo não conta com uma referência de onde encontrá-los ou de seu formato. Ou seja, dados não estruturados não possuem um formato predefinido para uso durante seu armazenamento, eles não possuem um modelo de dados que descreva como os dados são formatados ou qual é o seu tipo de dados. No geral, dados não estruturados são de forma livre, como, por exemplo, textos, áudios, imagens, vídeos, páginas da web ou documentos. (PADHY; PATRA; SATAPATHY, 2011; KONTIO; MARTTILA-KONTIO; HOTTI, 2015; RANJAN, 2019).

Mensagens e arquivos trocados por meio de mensagens instantâneas entre médicos e equipe médica podem ser classificadas como dados não estruturados, por se tratar de textos livres, imagens, vídeos e áudios.

\subsection{Dados estruturados}

O conceito sobre elementos estruturados começa em 1969 com a IBM, quando Charles Goldfarb, Edward Mosher e Raymond Lorie criaram uma linguagem chamada GML. O GML era uma linguagem de formatação para publicação de documentos, caracterizada por ser uma linguagem de marcação generalizada (KAY, 2005).

O GML inicialmente aceitou a edição e formatação de textos, além do compartilhamento de documentos pelos subsistemas. Além disso, também trouxe o conceito de um tipo de documento formalmente definido contendo uma hierarquia explícita de elementos estruturados (KAY, 2005). 
De acordo com Kuus (2014) dados estruturados podem ser definidos como informações que residem em campos fixos em um registro ou arquivo. Kontio, Marttila-Kontio e Hotti (2015) entendem que esses dados podem ser armazenados em uma estrutura que possui um formato que facilita ao usuário entender o significado dos dados ou definidos como dados que já estão armazenados em um banco de dados de uma forma ordenada (RANJAN, 2019).

Uma outra definição para dados estruturados é que estes consistem em metadados do documento e outras informações extraídas dos documentos, como links e texto. Ou seja, os dados estruturados apresentam uma organização que definem início e fim de uma representação de dados e o conteúdo armazenado nessa representação (CODD, 1970; MAIER, 1983; CHEN, 1988; CROFT; METZLER; STROHMAN, 2009).

Dessa forma, a organização oferecida pela estrutura proposta possibilita identificar e processar os dados de forma direta, sem a necessidade de um pré-processamento para identificação do conteúdo representado e de sua forma. Dessa maneira, os dados que possuem o mesmo formato e atendem às regras da representação podem ser processados de maneira mais rápida, ao se considerar que já é de conhecimento prévio o formato de representação do dado. Por outro lado, a estrutura escolhida para representar os dados limita a representação a um formato específico. Assim, variações nos dados podem não se ajustarem ao formato definido e demandarem modificações para representações.

\subsection{Dados semiestruturados}

A existência de formato prévio para representação dos dados facilita o uso de dados que atendem ao formato. Entretanto, mudanças nos dados a serem representados podem demandar mudanças em toda a estrutura definida. Os dados semiestruturados surgem para lidar com o desafio de manter uma estrutura que permita o processamento rápido dos dados e ofereça flexibilidade para lidar com variações tanto no formato quanto no conteúdo dos dados a serem representados. Isso é feito com o uso de marcadores que indicam qual dado que está representado e demais informações necessárias para o seu processamento. Os marcadores são utilizados em arquivos como XML e JSON (BUNEMAN, 1997).

Com essa abordagem, novos dados podem ser inseridos na representação, sem a necessidade de mudança em toda a estrutura, basta incluir um marcador para cada dado 
armazenado. Diferente dos dados estruturados, os dados semiestruturados, não necessariamente são conhecidos previamente. Entretanto, os marcadores proporcionam identificar os dados representados também de maneira direta (HAN et al., 2011; MANUKYAN; GEVORGYAN, 2016).

\subsection{Mineração de Textos}

A mineração de textos é o processo de busca ou extração as informações úteis dos dados textuais. É um processo que tenta descobrir conhecimento de textos não estruturados, extraindo automaticamente informações de diferentes recursos. (HEARST, 2003; VIJAYARANI; ILAMATHI; NITHYA, 2015).

\subsubsection{Técnicas de Pré-processamento de Textos}

O método de pré-processamento desempenha um papel muito importante nas técnicas e aplicações de mineração de texto. É o primeiro passo no processo de mineração de texto (VIJAYARANI; ILAMATHI; NITHYA, 2015).

As técnicas de pré-processamento são aplicadas logo na sequência da extração, e possuem o objetivo de se obter alguma massa textual, ou seja, de se aumentar a qualidade inicial dos dados. No geral, essas técnicas são as mais onerosas no processo de mineração de textos, uma vez que não existe uma única técnica que possa ser aplicada a fim de garantir um resultado satisfatório em todos os domínios (JUNIOR, 2008).

Além disso, no geral, o resultado de uma técnica é a entrada para execução de outra técnica.

A figura 1 abaixo explica as técnicas de pré-processamento de textos. Na figura é possível identificar que existem algumas etapas que são: (1) tokenização; (2) stemmer; (3) remoção de stop words (S.VIJAYARANI; JANANI, 2016).

Essas etapas fazem parte do pré-processamento de textos que serão explicados a seguir em conjunto com mais alguns conceitos. 
Figura 1 - Operações de pré-processamento de textos adaptado e traduzido de (S.VIJAYARANI; JANANI, 2016)

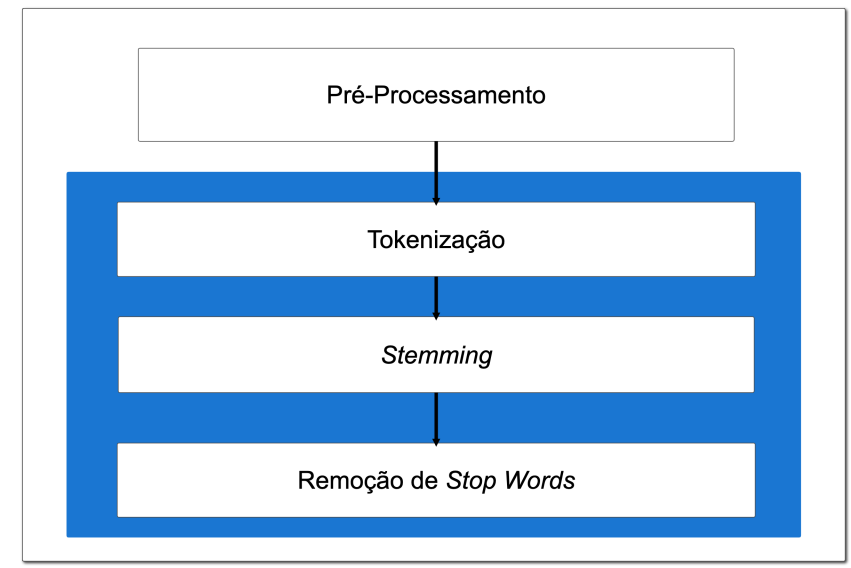

Fonte: Bianca Canezim Letti, 2019

Extração de informações a partir de dados de textos

O objetivo dos métodos de extração de informações (IE) é a extração de informações úteis do texto. Dessa forma, é possível identificar a extração de entidades, eventos e relacionamentos de texto semiestruturados ou não estruturados. Essa técnica lida com a identificação de palavras ou termos de recurso de dentro de um arquivo textual (CROFT; METZLER; STROHMAN, 2009; NENKOVA; MCKEOWN, 2012; SAGAYAM; S.SRINIVASAN; ROSHNI, 2012; BEHERA; KUMAR, 2015).

A atividade de extração de informações assume que as estruturas a serem extraídas, como, por exemplo, os tipos de entidades nomeadas ou se os tipos de relações estão bem definidos. Uma entidade nomeada é uma sequência de palavras que tem significado ou é utilizada para referenciar algo de interesse. Geralmente, essas entidades podem ser classificadas como pessoas, organizações e locais (CROFT; METZLER; STROHMAN, 2009; NENKOVA; MCKEOWN, 2012).

Em algumas situações, não é possível saber antecipadamente as estruturas das informações exatas a serem mineradas e isso é apontado nesse tipo de técnica como uma limitação.

Para extrair informações são realizadas duas etapas: a primeira delas, as ferramentas devem ser capazes de reconhecer as estruturas no texto, no qual deve ser possível reconhecer palavras que são entidades e conjuntos de palavras que descrevem um conceito. 
A segunda etapa é extrair informações do texto. Isso pode ser feito por meio do reconhecimento de termos, mas, com frequência, inclui o reconhecimento de entidades nomeadas, como nomes de pessoas, extração de fatos como os relacionamentos entre termos ou entidades. De forma mais generalista, é preciso realizar o reconhecimento de entidades nomeadas e a relação de extração (CROFT; METZLER; STROHMAN, 2009; NENKOVA; MCKEOWN, 2012; CLARK, 2013).

A extração de entidades nomeadas consiste em determinar automaticamente a continuidade de fragmentos do texto, chamadas de entidades nomeadas, as quais se referem a unidades de informação como pessoas, lugares geográficos, nomes de organizações e datas, por exemplo (POIBEAU, 2009).

A extração de entidades nomeadas é baseada em duas metodologias: (a) regras de correspondência de padrões e (b) aprendizado de máquina (NADEAU; SEKINE, 2007).

A primeira abordagem define regras linguísticas para detectar cada tipo de entidade. Essas regras usam marcadores lexicais, dicionários de nomes próprios e dicionários de linguagem geral para identificar as entidades nomeadas. Essa abordagem consome tempo durante o desenvolvimento, mas dá resultados muito bons, enquanto, como desvantagem, essa abordagem apresenta falta de generalização, o que limita sua extensão a novos domínios. A segunda abordagem, a de aprendizado de máquina, demonstrou resultados notáveis nos domínios gerais e são promissores para a extração de informações médicas, mas exigem um corpo grande para treinamento, que são caros e demorados no treinamento dos modelos (POIBEAU, 2009; BARIGOU; ATMANI; BELDJILALI, 2012).

\subsubsection{Sumarização de textos}

A sumarização de texto é o processo de criar automaticamente uma versão compactada de um determinado texto que fornece informações úteis para o usuário (BEHERA; KUMAR, 2015).

No geral, há momentos em que não é possível ler todos os documentos para se resumir o contexto de textos não estruturados.

A sumarização de texto envolve vários métodos que empregam categorização de texto, como redes neurais, árvores de decisão, gráficos semânticos, modelos de regressão ou lógica fuzzy. No entanto, todos esses métodos têm um problema comum, ou seja, a 
qualidade do desenvolvimento de classificadores é variável e altamente dependente do tipo de texto que está sendo resumido (BEHERA; KUMAR, 2015).

\subsubsection{Tokenização}

Tokenização é o processo de dividir um texto em palavras, frases, símbolos, espaços em branco ou outros elementos significativos chamados tokens. O objetivo da tokenização é a exploração das palavras em uma frase. A lista de tokens se torna entrada para mais processamento, como análise ou mineração de texto. A tokenização é útil tanto em linguística (na qual é uma forma de segmentação de texto), quanto em ciência da computação, na qual faz parte análise lexical (CASTELLANO et al., 2007; S.KANNAN; GURUSAMY, 2014; VERMA; RENU; GAUR, 2014).

O propósito da tokenização é dividir o conteúdo em pequenos pedaços de texto utilizáveis (tokens). Os tokens geralmente representam palavras únicas, mas, o que constitui um pequeno pedaço utilizável pode ser específico por aplicação. A primeira abordagem mais comum para tokenizar é dividir uma string com base na ocorrência de espaço em branco, como espaços e quebras de linha (INGERSOLL; MORTON; FARRIS, 2013).

O exemplo abaixo ilustra um fluxo de texto ainda sem passar pelo processo de tokenização.

Figura 2 - Texto sem passar pelo processo de tokenização adaptado de (INGERSOLL; MORTON; FARRIS, 2013)

\begin{tabular}{|l|c|c|c|c|c|c|c|c|c|c|c|c|c|}
\hline Eu & não & acredito & que & $\circ$ & Carolina & Hurricanes & tenha & vencido & a & Stanley & Cup & de & $2005-2006$. \\
\hline
\end{tabular}

Fonte: Bianca Canezim Letti, 2019

O exemplo abaixo ilustra o mesmo fluxo de texto ao passar pelo processo de tokenização.

Figura 3 - Texto tokenizado adaptado de (INGERSOLL; MORTON; FARRIS, 2013)

\begin{tabular}{|c|c|c|c|c|c|c|c|c|c|c|c|c|c|c|c|}
\hline Eu & não & acredito & que & $\circ$ & Carrolina & Hurricanes & tenha & vencido & a & Stanley & Cup & de & 2005 & - & 2006 \\
\hline
\end{tabular}

Fonte: Bianca Canezim Letti, 2019 


\subsubsection{Filtering}

Por definição, o processo de filtragem retira a informação de interesse e descarta o restante (CROCCO; LOH, 2010).

No contexto de mineração de textos, o processo de filtragem se dá pela remoção dos caracteres de pontuação. Esse processo é importante pois contribui para que as palavras não sejam diferenciadas ou associadas por um item de pontuação. Desse modo, é também removendo a pontuação, que técnicas posteriores que precisam ser aplicadas, possam ser aplicadas.

Esses caracteres, de maneira geral, não alteram o significado do documento, apesar da remoção da pontuação poder alterar o significado das frases, pois o significado do documento fica inalterado, o viés do documento é definido pelas palavras mais significantes no texto e os caracteres de pontuação não tem valor para o seu processamento (HACK et al., 2013).

\subsubsection{Stemming}

O stemming é o processo de confluir as formas variantes de uma palavra em uma comum representação, o "caule", ou seja, cortar o radical das palavras. Por exemplo, as palavras: "apresentação", "apresentado", "apresentando" poderiam ser reduzidas a uma representação comum "apresentar" (S.KANNAN; GURUSAMY, 2014).

A figura 4 ajuda a ilustrar esse processo. Na coluna da direita, na qual a técnica de stemming já foi aplicada, sobra somente o "caule".

O stemming de palavras é um recurso usado pelos sistemas atuais de indexação, pesquisa e nos sistemas de recuperação de informações para garantir que variantes de palavras não sejam deixadas de fora quando o texto é recuperado (LOVINS, 1968).

O processo é usado na remoção de sufixos derivativos, bem como de inflexões, ou seja, sufixos que alteram a forma das palavras e suas funções gramaticais, para que as variantes das palavras possam ser confundidas nas mesmas "raízes" ou "hastes" (BALAKRISHNAN; LLOYD-YEMOH, 2014). 
Figura 4 - Representação da técnica de stemming adaptada de (FILHO, 2016)

\begin{tabular}{|ll|}
\hline Palavra & Stemming \\
\hline quilo & quil \\
quilométricas & quilométr \\
quilométricos & quilométr \\
quilômetro & quilômetr \\
quilômetros & quilômetr \\
quilos & quil \\
química & químic \\
químicas & químic \\
químico & químic \\
químicos & químic \\
quimioterapia & quimioterap \\
quimioterápicos & quimioteráp \\
\hline
\end{tabular}

Fonte: Bianca Canezim Letti, 2019

A figura 5 demonstra a aplicação da técnica em um texto. Nessa imagem é possível conferir a remoção dos radicais e a permanência dos caules.

Figura 5 - Representação da técnica de stemming em um texto adaptada de (HONORATO et al., 2004)

Mucosa toda extensão com presença pontos placas esbranquiçadas (monilíase)

Mucosa terço distal com presença erosão linear

Calibre distensibilidade normais

Após aplicação do

algoritmo de stemming

Muc tod extens com presenc pont plac esbranquic (moniliase)

Muc terc dist com presenc eros lin

Calibr distensibil norm

Fonte: Bianca Canezim Letti, 2019

\subsubsection{Stop Words}

Stop words são uma divisão da linguagem natural. Na visão de Vijayarani, Ilamathi e Nithya (2015), o motivo pelo qual palavras de parada, ou stop words, como são mais conhecidas, devem ser removidas de um texto, é porque não necessariamente são importantes para análise. A remoção de stop words reduz a dimensionalidade do termo espaço. As mais comuns palavras em documentos de texto são artigos, preposições, substantivos, pronomes, dentre outros exemplos e que não dão o significado dos documentos a serem analisados. Estas palavras são tratadas como stop words. 
Já na opinião de S.Kannan e Gurusamy (2014), as stop words são palavras nos documentos que são muito recorrentes, mas são essencialmente sem sentido, como quando são utilizadas para unir sentenças. É comumente entendido que stop words não contribuem para o contexto ou conteúdo de documentos textuais. Devido a sua alta frequência de ocorrência, sua presença na mineração de texto apresenta um obstáculo à compreensão do conteúdo dos documentos.

A figura 6 mostra um exemplo da remoção de stop words em um texto.

Figura 6 - Representação da técnica de remoção de stop words em um texto adaptada de (HONORATO et al., 2004)

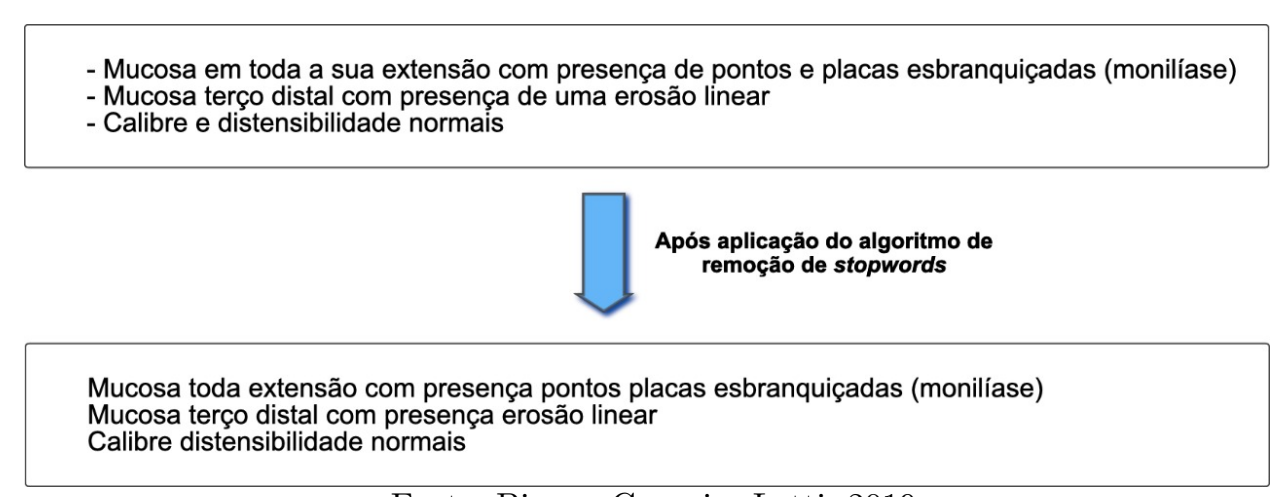

Fonte: Bianca Canezim Letti, 2019

\subsubsection{Frequência de palavras ou termos}

Frequência de termos é definida como uma contagem de termos e suas respectivas ocorrências em um documento específico. Quanto maior a frequência de um termo, significa que esse termo tem importância para o contexto (AAMIR; BHUSRY, 2016).

A frequência do termo representa o número de ocorrências de um determinado termo j no documento i. A frequência do documento, por sua vez, representa o número de documentos em uma coleção de n documentos nos quais o termo j ocorre (CHEN et al., 1997).

É possível assumir que quanto mais vezes uma palavra ocorre, mais significado ela tem para contribuir com esse documento. Um documento que se refere a "asas" e "leme" com frequência pode ser mais relevante para um problema que envolva aviões a jato ou viagens aéreas do que dizer que o documento se refere frequentemente a "gatos" e "gravidade" (LANE; HOWARD; HAPKE, 2019). 


\section{Materiais e Métodos}

Este trabalho aborda o tema de aplicativos para apoio à comunicação entre equipes de saúde. Para atingir esse fim, foram desenvolvidas atividades relacionadas à compreensão dos desafios enfrentados na comunicação entre equipes de saúde e os recursos disponíveis para esse fim. A questão de falhas de tratamento causadas por problemas de comunicação, além de ser uma das motivações do trabalho também reforçou a avaliação dos recursos e desafios presentes no contexto da atuação da equipe de saúde. Portanto, este trabalho seguiu a metodologia, a seguir, durante o seu desenvolvimento:

- Levantamento bibliográfico para avaliação da literatura referente aos aplicativos voltados para o apoio do acompanhamento de pacientes;

- Estudo do contexto de comunicação entre equipes de saúde, com foco nos desafios, limitações e falhas de comunicação;

- Avaliação e escolha de técnicas para processamento de texto;

- Obtenção e avaliação de textos de simulações de trocas de mensagens entre equipes de saúde;

- Definição de abordagem para identificação e representação de termos a serem acompanhados durante trocas de mensagens;

- Proposição de arquitetura para processamento e representação de mensagens trocadas entre equipes de saúde;

- Definição de formato para apresentação dos dados monitorados;

- Implementação da arquitetura proposta;

- Desenvolvimento de aplicativo para utilização e avaliação da arquitetura proposta;

Para a etapa de implementação da arquitetura proposta e desenvolvimento do aplicativo, utilizou-se o método de prova de conceito.

De acordo com Kendig (2015) o conceito em "prova de conceito" se refere a qualquer ideia que pode se aplicar a uma classe de fenômenos. A "prova" parece ser uma possibilidade prova que é demonstrada obter na prática experimental. Isso prova a causal hipótese de conexão, estrutura proposta, função sugerida ou metodologia. A abordagem adotada na pesquisa é obtida em pelo menos um caso real, no caso de teste. A noção de pesquisa de prova de conceito é estruturada em termos de um tipo particular de pesquisa que visa 
responder a uma pergunta cuja resposta tenha ampla aplicabilidade em áreas além da testada. Ao fazer isso, a pesquisa fornece justificativa na prática potencial dessa pesquisa.

Uma prova de conceito é definida como uma fase no desenvolvimento em que o hardware experimental é construído e testado para explorar e demonstrar a viabilidade de um novo conceito. (AERONAUTICAL. . , 1969).

Em sua pesquisa, Kruize (2017) também utiliza o método de prova de conceito aplicado para software.

Dessa forma, através da prova de conceito foi possível implementar um modelo de arquitetura não exaustivo para realizar uma possibilidade prova, uma prática experimental, de acordo com o objetivo de pesquisa proposto. A implementação do aplicativo fez parte desse projeto de pesquisa para que fosse possível realizar a simulação de entrada de dados por meio da troca de mensagens entre os médicos, mas a arquitetura não está limitada somente a essa interface, por ter sido construída de forma modular.

Este trabalho de arquitetura fez uso dos seguintes recursos tecnológicos:

- Linguagem de desenvolvimento Java 1.8.0_232. Utilizada para desenvolvimento dos módulos da arquitetura disponíveis no servidor (ORACLE, 2019);

- Banco de dados orientado a documentos MongoDB (mLab) versão 3.6.9. Ferramenta usada para o armazenamento dos dados gerados durante a troca de mensagens gerenciada pelo aplicativo desenvolvido (INC, 2018);

- Node.js na versão 8.11.4. usado para desenvolvimento das API's para integração da arquitetura com aplicativos de troca de mensagens (DAHL, 2018);

- Quickblox. Plataforma de apoio a criação de aplicativos de mensagens instantâneas. Usado na implementação dos módulos de troca de mensagens do aplicativo móvel. (QUICKBLOX, 2018);

- Xamarin com forms 4.4. Plataforma para criação de aplicativos móveis em multiplataforma. Em conjunto com o Visual Studio 8.4 foi utilizado como ambiente para o desenvolvimento do aplicativo healthMessage na versão para Android e em conjunto com Xcode 11, compôs o ambiente para desenvolvimento da versão iOS do aplicativo (MICROSOFT, 2011; APPLE, 2019; FILHO, 2019).

- Heroku na stack 18 com instância nos Estados Unidos da América. Serviço de servidores de nuvem (LINDENBAUM; WIGGINS; HENR, 2007). 
O aplicativo desenvolvido, denominado de healthMessage, utilizou a plataforma para desenvolvimento de aplicativos móveis híbridos chamada Xamarin. Com ela, o aplicativo pode ser gerado tanto para dispositivos Android, quanto para dispositivos $i O S$. Dessa forma, o aplicativo pode ser utilizado por dispositivos com os dois principais sistemas operacionais para smartphones atualmente.

As tecnologias utilizadas no processo de validação estão representadas pela figura 7 . Nela, o uso de cada recurso tecnológico é representado por uma cor. A arquitetura proposta neste trabalho independe de tecnologia específica. Portanto, as tecnologias utilizadas atenderam critérios de compatibilidade e disponibilidade de uso com a plataforma Xamarin e com demais componentes utilizados no desenvolvimento do servidor de aplicações.

Figura 7 - Representação das tecnologias usadas no processo de validação

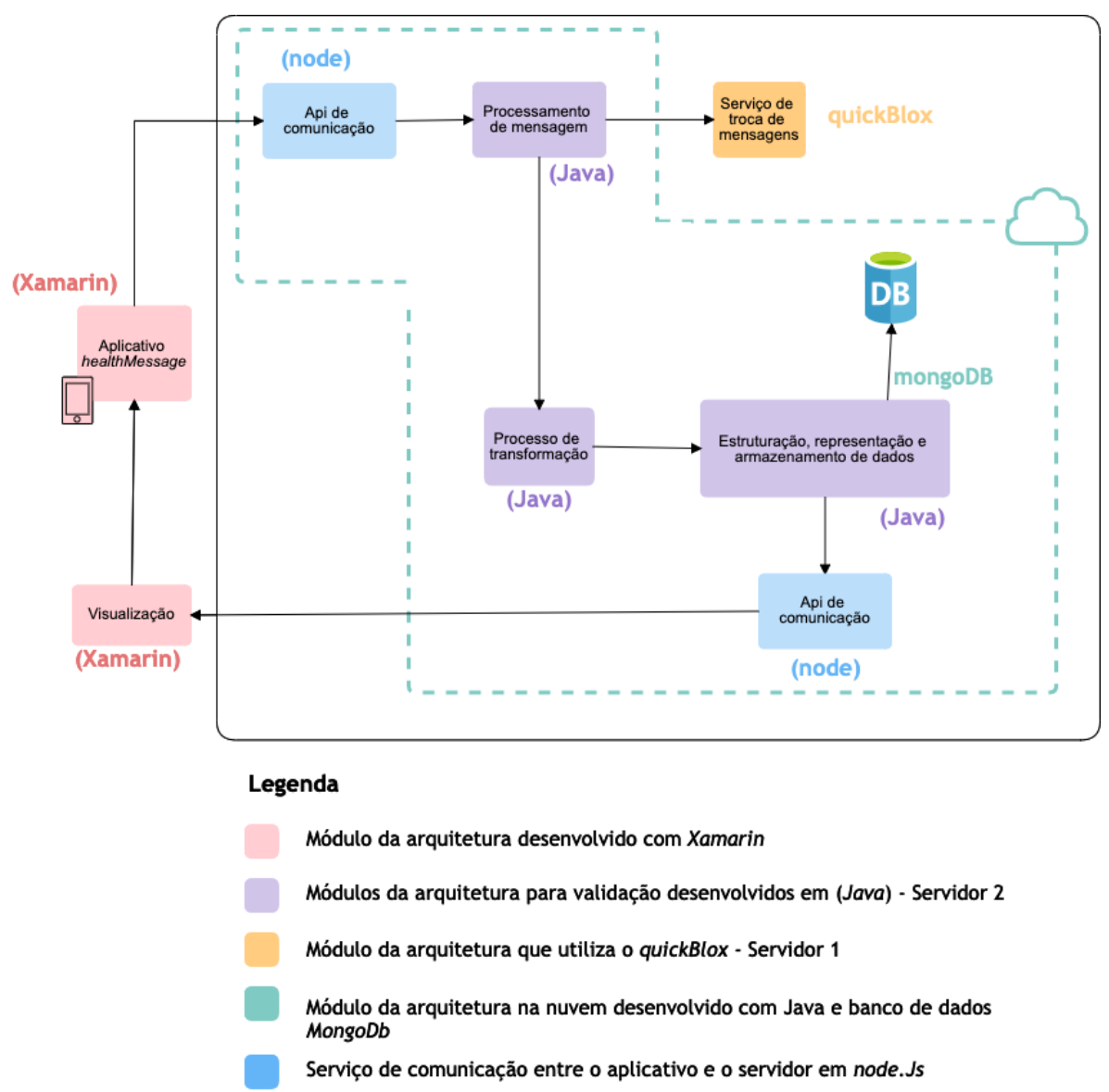

Fonte: Bianca Canezim Letti, 2019

Os módulos em vermelho representam a parte da arquitetura que utiliza o Xamarin para construção do aplicativo e que é utilizado como método de entrada e saída.

Em roxo é mostrado o módulo da arquitetura que utiliza o servidor desenvolvido para validação. 
A parte amarela representa o uso do serviço de mensageria oferecido pela plataforma QuickBlox.

Em verde está representado o armazenamento dos dados no banco de dados orientado a documentos mongo $D B$.

E, por fim, a linha pontilhada em cor azul claro mostra os módulos disponíveis no servidor de processamento em nuvem computacional Heroku. 


\section{Arquitetura}

Este trabalho propõe uma arquitetura para representar e apoiar a comunicação entre médicos e equipes de saúde. Tal arquitetura visa contribuir com a comunicação no contexto de interações de membros de uma equipe para o acompanhamento de pacientes, conforme apresenta a Figura 8. Na figura estão descritos os atores dessa interação, sendo:

- Médico: a pessoa que vai interagir com pacientes, mas também se comunicará com a equipe de saúde com a qual está envolvido.

- Equipe de saúde: a equipe que atua no mesmo hospital que um determinado médico e que interage com esse médico na troca de turnos, falando sobre o estado de pacientes e segundas opiniões médicas.

- Pacientes: Os indivíduos que estão recebendo tratamento em determinado hospital ou clínica.

- Exames: Um exemplo de interação realizada entre médico e paciente que demonstre necessidade de fala, registro ou segunda opinião com a equipe de saúde.

A figura demonstra a dinâmica de interação entre médicos e a equipe médica para lidar com o acompanhamento e tratamento dos pacientes. No canto superior direito da figura, um médico visita um paciente em um leito e solicita exames laboratoriais para avaliar o quadro clínico do paciente. As informações referentes ao paciente, assim como os exames solicitados e seus resultados, podem ser visualizados pela equipe médica e podem ser enviados para o paciente.

Após o diagnóstico, inicia-se o processo de tratamento com o paciente, e é durante esse processo que o médico interage com a equipe médica discorrendo diariamente sobre o estado atual do paciente e, quando necessário, solicita segundas opiniões a outros médicos. Por sua vez, o paciente também interage com a equipe médica, uma vez que, os médicos trabalham em turnos para acompanhar seus pacientes.

Durante o curso desse ciclo de acompanhamento, as atividades se repetem e as informações são trocadas pelos membros da equipe de saúde. 
Figura 8 - Exemplo de dinâmica de interação humana entre médicos e equipe médica sobre pacientes e exames

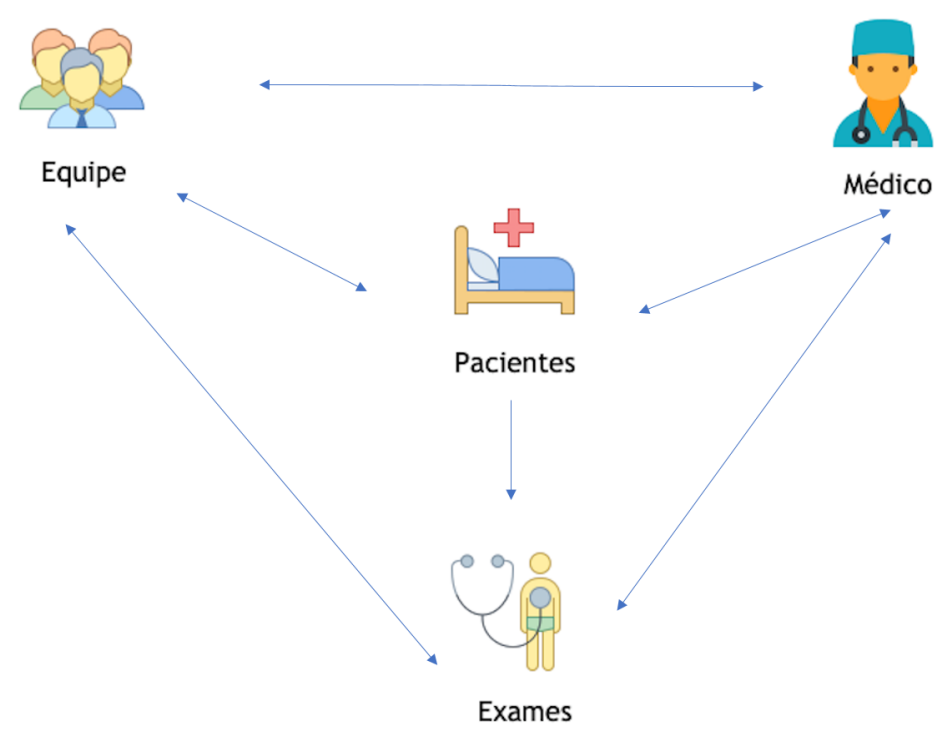

Fonte: Bianca Canezim Letti, 2019

Nesse contexto, a comunicação é fundamental desde o processo de diagnóstico até a conclusão do tratamento, principalmente entre o médico e a equipe de apoio. Atualmente os médicos também fazem uso de aplicações de mensageria instantânea para manter a comunicação ágil (BOULOS; GIUSTINI; WHEELER, 2016; GIORDANO et al., 2017).

Dessa forma, em um contexto de conversação que caracterizam mensagens não estruturadas trocadas entre médicos e equipe médica, em aplicativos de mensageria instantânea, não preparados e estruturados para o ambiente médico, as informações que são relevantes e importantes sobre pacientes, exames, diagnósticos e tratamentos acabam sendo facilmente perdidas ou muito custosamente buscadas nessas aplicações.

A arquitetura proposta nessa pesquisa permite que, por meio da troca de mensagens entre médicos e sua equipe, as informações sejam identificadas e representadas de forma semiestruturada, como forma de organizar entidades no texto que devam ser monitoradas.

A Figura 9 ilustra a arquitetura proposta. A conversação é o de processo troca de mensagens entre usuários e que fornece os dados de entrada. Após essa primeira etapa, a arquitetura processa a mensagem.

Nessa fase de processamento, a arquitetura se divide em duas etapas: uma delas é o armazenamento do texto base em um banco de dados relacional, para constituir, posteriormente, a fase de troca de mensagens, assim como ela é, por meio de um chat, 
por exemplo. A outra é a parte que caracteriza a transformação do texto recebido. O texto é pré-processado e transformado. Em seguida, é realizada a representação dos termos identificados como relevantes para monitoramento.

Esta etapa intermediária, de representação de termos, proporciona que o texto seja semiestruturado e armazenado em um banco de dados não relacional, como um banco orientado a documentos. Uma vez gerado o documento, o dado pode ser fornecido em diferentes formatos, por exemplo, um Json, XML, CSV ou um TXT.

Na sequência, a arquitetura prepara a apresentação dos termos representados. Essa etapa é dividida em visualização e aprendizado. A parte de visualização prepara a apresentação dos termos monitorados de forma gráfica e consolidada. Ou seja, um exame cujos resultados em valores numéricos foram monitorados pela arquitetura tem sua evolução apresentada na forma de gráfico. Os dados podem ser compartilhados com o uso de $A P I ' s$

A parte de aprendizado é o módulo responsável pelo aprendizado de máquina. Ele é o responsável por processar as mensagens trocadas e aprender para apoiar os médicos durante as conversas no chat, por meio de sugestões de doenças, sugestões de valores de exames, quando algum valor estiver fora do comum, entendendo que há um possível erro de digitação. Além de gerar alertas baseados em comportamentos, que podem levar a uma piora no tratamento do paciente, e que ainda não esteja visível para os médicos, se comparado com casos anteriores semelhantes, por exemplo. 
Figura 9 - Processo da arquitetura

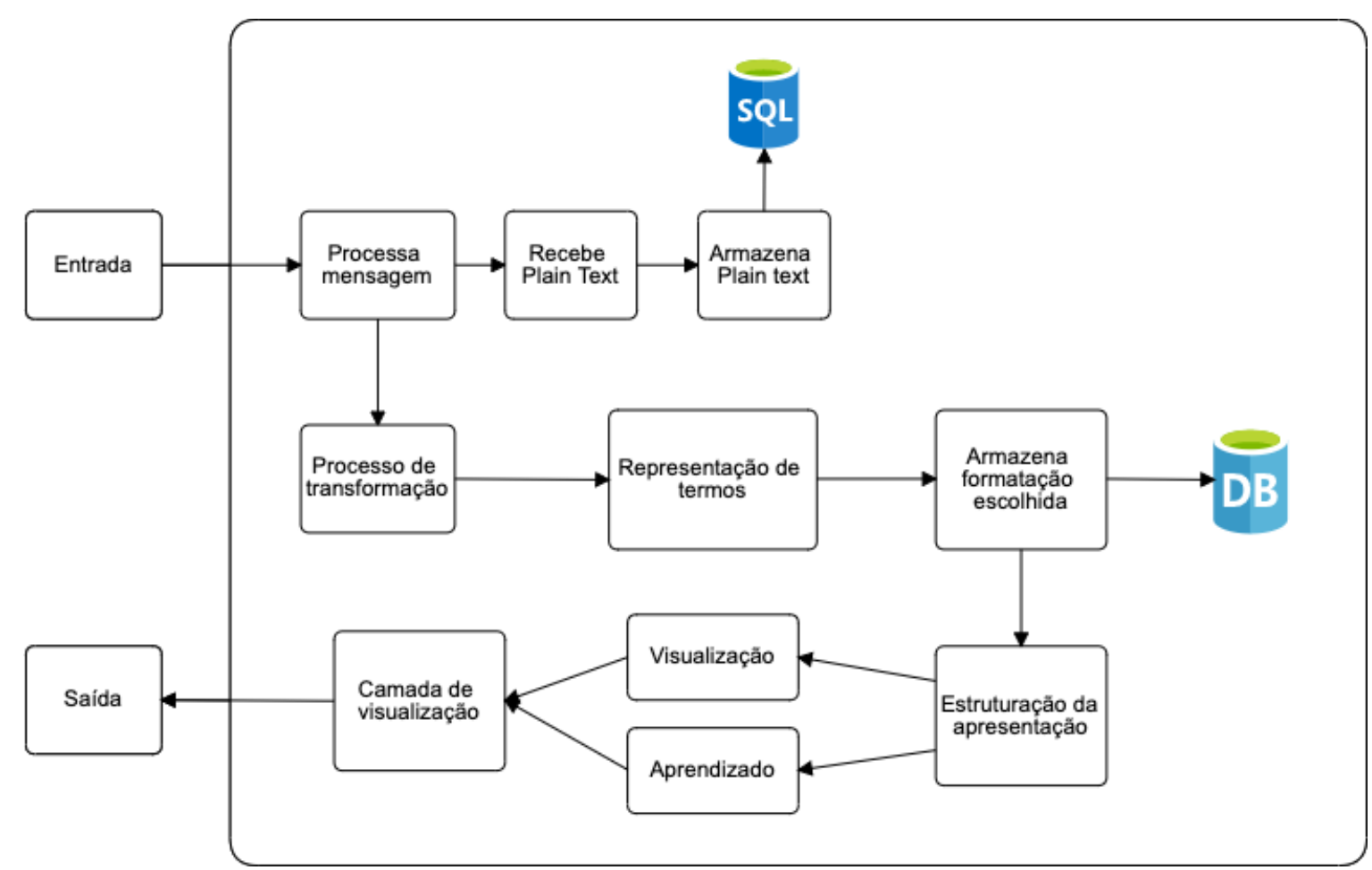

Fonte: Bianca Canezim Letti, 2019

A figura 10 apresenta uma divisão na arquitetura proposta em quadrantes com cores.

O quadrante de número 1, representado pela cor laranja, corresponde ao processo de troca de mensagens. Essa troca pode ser executada por aplicativos de mensageria instantânea, como o WhatsApp.

O quadrante de número 2, por sua vez, representa a etapa de transformação e semiestruturação de dados. Nessa etapa, explica-se sobre a parte da arquitetura que realiza o processo de transformação e organização.

O quadrante de número 3 demonstra o processo de apresentação e aprendizado. Nesta etapa, é possível realizar sugestões e proposições da arquitetura e preparar os dados semiestruturados para serem apresentados na camada de saída da arquitetura. 
Figura 10 - Processo da arquitetura detalhado

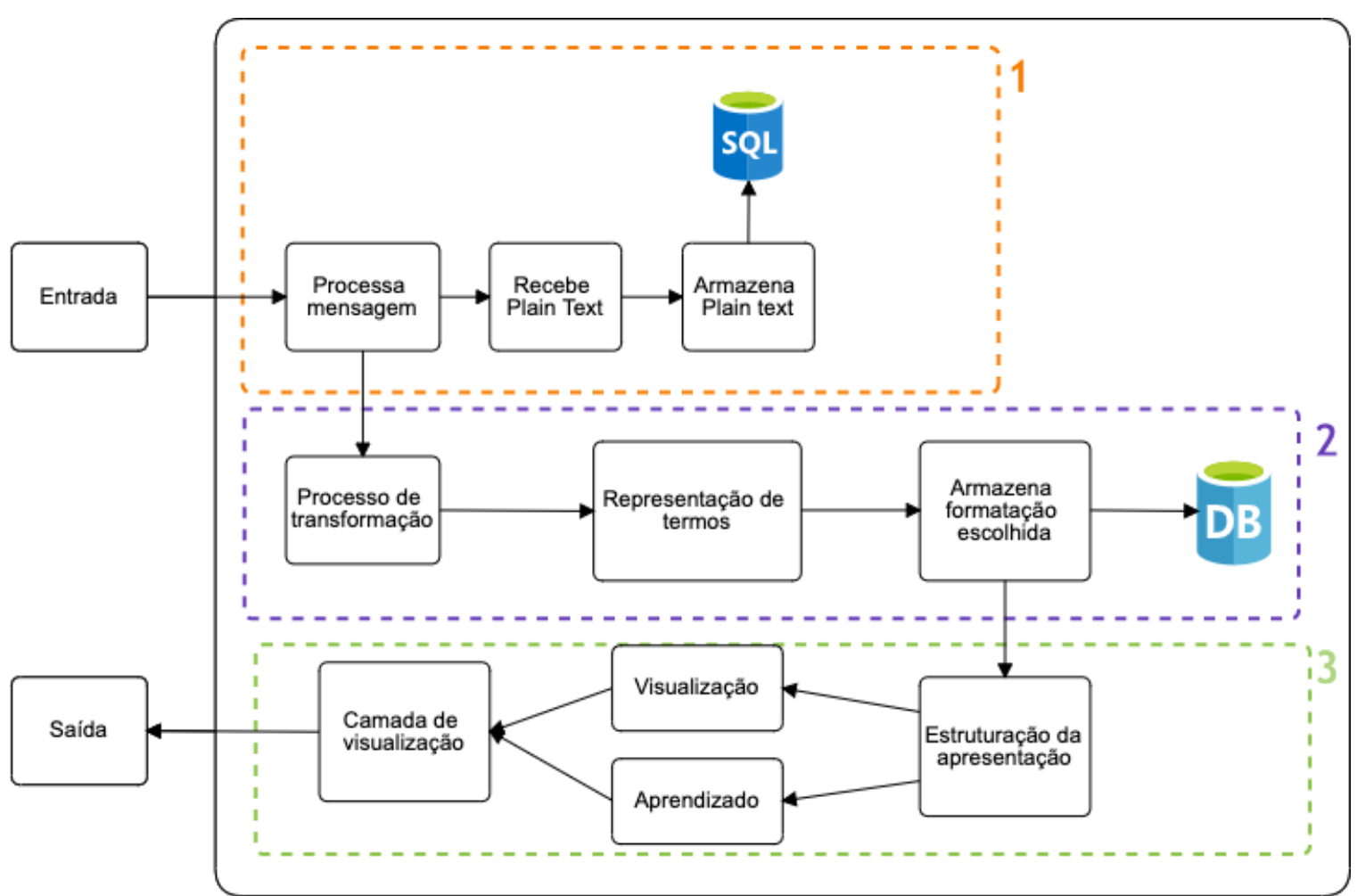

Fonte: Bianca Canezim Letti, 2019

\subsection{Processo de Troca de Mensagens}

As mensagens instantâneas são conversas estabelecidas de forma virtual entre duas ou mais pessoas. No entanto, como constituem conversações sem nenhuma estruturação, acabam caracterizando trocas e armazenamentos de dados não estruturados, conforme apresentado na seção 4 de fundamentação. Esses dados são armazenados em bancos de dados.

A figura 11 exemplifica como é feita a troca de mensagens na proposição feita para a arquitetura, na qual o médico 1 se comunica com o médico 2, mediante uma interface de entrada e saída, nesse caso, um aplicativo, e por meio da comunicação feita por API's, esse serviço armazena no banco de dados as informações trocadas nas mensagens sem alterá-las. 
Figura 11 - Processo de troca de mensagens detalhado

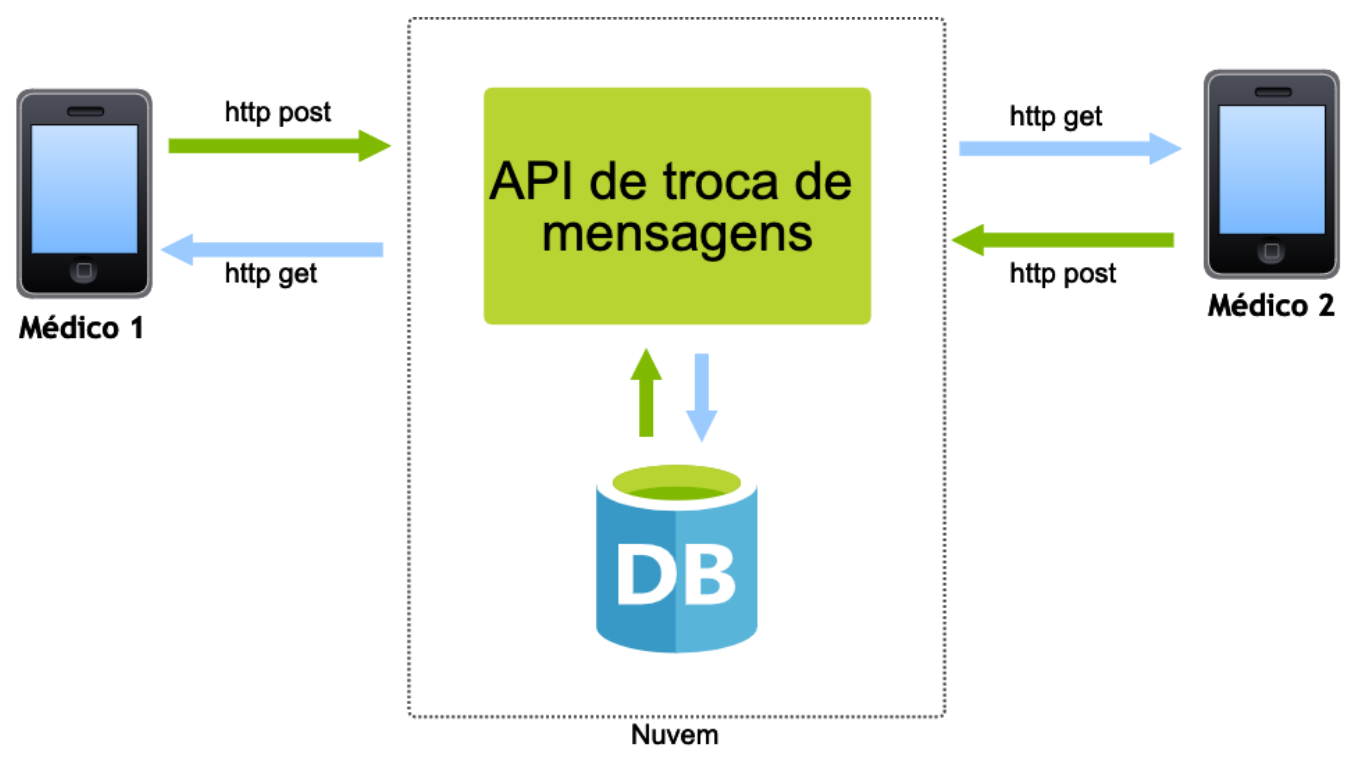

Fonte: Bianca Canezim Letti, 2019

\subsection{Processo de transformação}

A etapa de transformação está apresentada em detalhes na figura 12. Nela, o processo de transformação é apresentado em cinco etapas: (1) extração do texto, (2) módulo de acompanhamento de marcadores, (3) sumarização, (4) cálculo da frequência de palavras e (5) organização. 
Figura 12 - Processo detalhado do quadrante dois da arquitetura sobre transformação

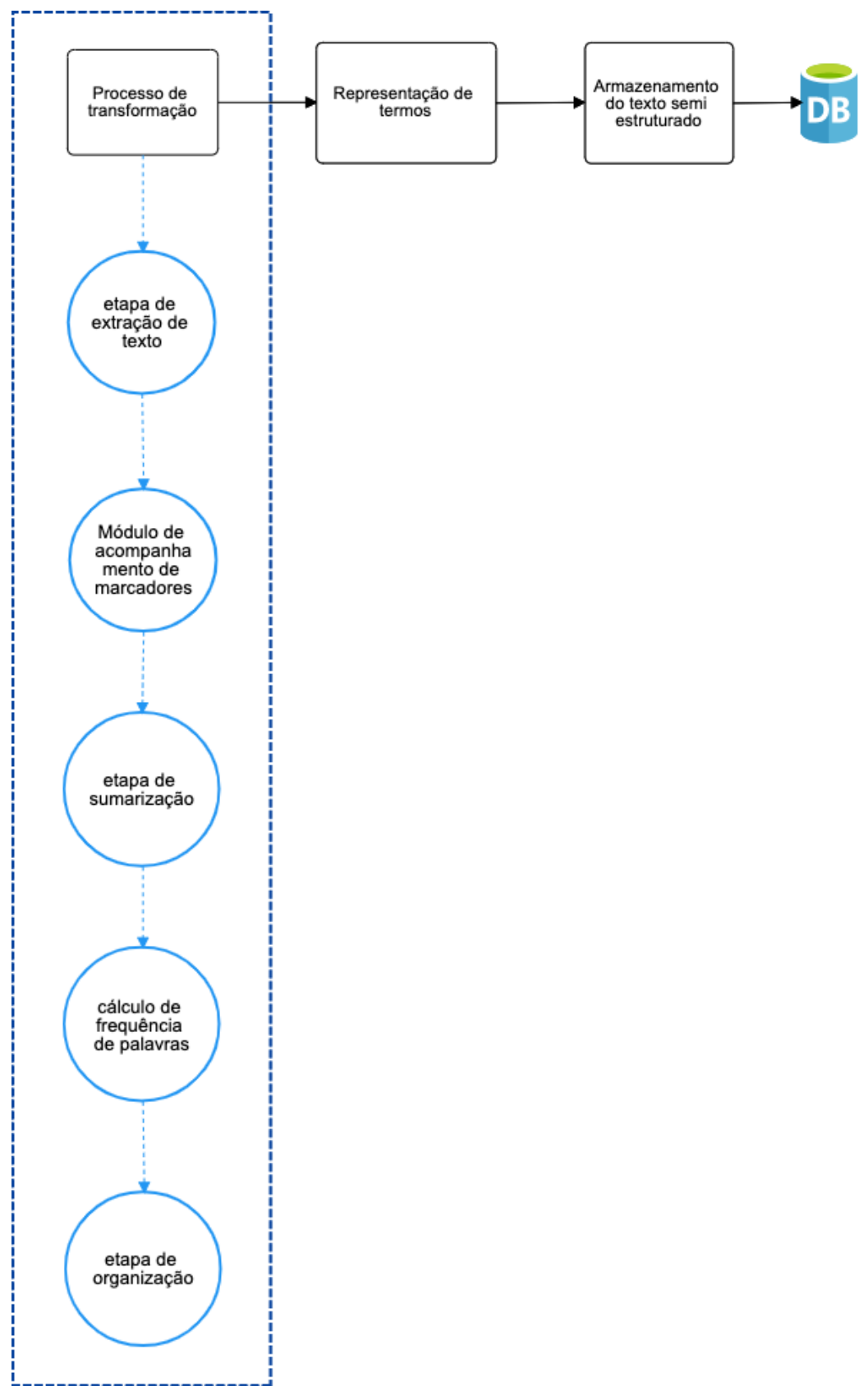

Fonte: Bianca Canezim Letti, 2019

6.2.1 (1) Etapa de extração do texto

Essa etapa é realizada na arquitetura através da identificação de termos relevantes de um arquivo de mensagens instantâneas trocadas pela equipe.

Para o contexto desta pesquisa, como técnica utilizada para extração do texto, o algoritmo realizado representa, através de marcadores, as expressões que são importantes 
para os médicos e equipe. Dessa forma, o médico e equipe podem ir realizando as marcações conforme vão interagindo na conversa.

A tarefa de marcação segue a ideia do uso de símbolos que precedem as palavras para indicar sua categoria. Essa abordagem é conhecida e nessa pesquisa o conjunto de símbolos foi ampliado para atender as necessidades do contexto de mensagens da área da saúde.

6.2.2 (2) Módulo de acompanhamento de marcadores

Esse trabalho definiu três tipos de marcadores a serem utilizados para monitoramento de termos de interesse de uma equipe de saúde, sendo eles:

- \& - Define a identificação de um paciente. O marcador indica a qual paciente a conversa se refere. Ele é utilizado para agregar todas as mensagens e marcadores para um paciente específico. A identificação pode ser feita com o uso de números e letras, cabe aos usuários definirem a forma como desejam identificar os pacientes;

- Sintaxe: \&descritor ou \& descritor - O primeiro termo após o marcador \& é utilizado para identificar o paciente e relacionar as informações contidas na mensagem, até que um novo marcador de paciente seja inserido no texto. Ex.: \&1234 ou \&ABC \&Maria;

- \% - Indica doenças ou sintomas a serem destacados - Para tanto, a palavra subsequente ao marcador será listada no resumo do paciente.

- Sintaxe: \%descritor ou \% descritor - O termo que segue o marcador \% é utilizado para identificar sintomas ou doenças a serem incluídos no resumo do paciente. Ex.: \%diabetes ou \%vômito \%febre;

- \# - Referencia exames cuja evolução de valores será acompanhada. O marcador permite reunir todos os valores compartilhados de um exame.

- Sintaxe: \#descritor valor ou \# descritor termo valor ou \# descritor termo termo valor - Esse marcador se diferencia dos demais ao permitir que valores sejam associados ao marcador. Portanto, o marcador possui sintaxe composta pelo descritor do exame a ser referenciado e o valor a ele atribuído. Além disso, o marcador aceita que termos sejam incluídos entre o descritor do 
exame e seu valor. Essa abordagem proporciona que comentários, comuns em mensagens informais, sejam utilizados e é uma abordagem mais flexível. Por exemplo, uma mensagem na qual é informado que a creatinina subiu para 3 poderia ser representada de variadas formas como a seguir: "\#creatinina subiu para 3", "\#creatinina 3", "\#creatinina = 3", "\#cr= 3".

\subsection{3 (3) Etapa de sumarização}

A etapa de preparação e sumarização é subdividida nas seguintes partes: filtragem, na qual são removidas as pontuações, remoção das stop words, na qual artigos e preposições são removidas e remoção dos radicais, definido como stemmer, conforme explicação no capítulo 4 de fundamentação.

$\mathrm{Na}$ arquitetura proposta, foi percebido que a utilização da remoção de stop words e o uso de stemmer no contexto médico poderiam remover termos importantes, como abreviaturas usadas pela equipe e mesmo causar ambiguidade ao substituir a palavra por sua raiz. Portanto, tais abordagens não são utilizadas.

Exemplos que ajudam a ilustrar este processo são as seguintes frases:

- "O paciente 1 está morrendo"

- "A acidose tubular estava boa"

No primeiro exemplo, a utilização do stemmer pode tratar de forma igual às palavras "morrendo", "morrer" e "morreu". O que causaria limitação na agregação de valores e mensagens. No segundo exemplo, a utilização da técnica de pré-processamento de textos, por meio da remoção de stop words, poderia interferir no processo, pois retiraria a palavra "boa" da frase e limitaria a representação das mensagens.

\subsection{4 (4) Cálculo de frequência de palavras}

Além das técnicas de pré-processamento, a arquitetura também realiza uma etapa de cálculo de frequência de palavras, conforme descrito na seção 4 sobre fundamentação.

Baseado na frequência de palavras, os termos relevantes podem ser acompanhados seja pela maior ou menor frequência de ocorrência. Dessa forma, a quantidade de palavras 
monitoradas pela arquitetura é expandida com o uso da avaliação da frequência das palavras. Assim, mesmo termos não definidos previamente podem ser acompanhados.

\subsection{5 (5) Etapa de organização}

A etapa de organização consiste em, após pré-processar o texto por meio da extração, acompanhamento dos marcadores, sumarização e do cálculo da frequência de palavas, é feita a organização das informações relevantes sumarizadas para que seja possível repassá-las para a próxima camada: a camada de semiestruturação.

Essa etapa é a responsável por pegar as informações finais após a passagem por cada uma das etapas acima e organizar para que possam ser semiestruturadas.

\subsection{Processo de semiestruturação de dados}

A etapa seguinte, por sua vez, consiste na semiestruturação dos dados. Nessa etapa, a arquitetura aceita múltiplos formatos de destino final, a fim de que o formato não seja um limitante para semiestruturação dos dados e que possa servir como uma ferramenta de conexão com outras ferramentas.

Esse processo é finalizado na etapa de armazenamento. Dado à formatação escolhida dentro da arquitetura proposta, os dados organizados e semiestruturados são armazenados para posterior utilização.

A figura 13 representa esse processo de forma detalhada. 
Figura 13 - Processo detalhado do quadrante dois da arquitetura sobre semiestruturação de dados

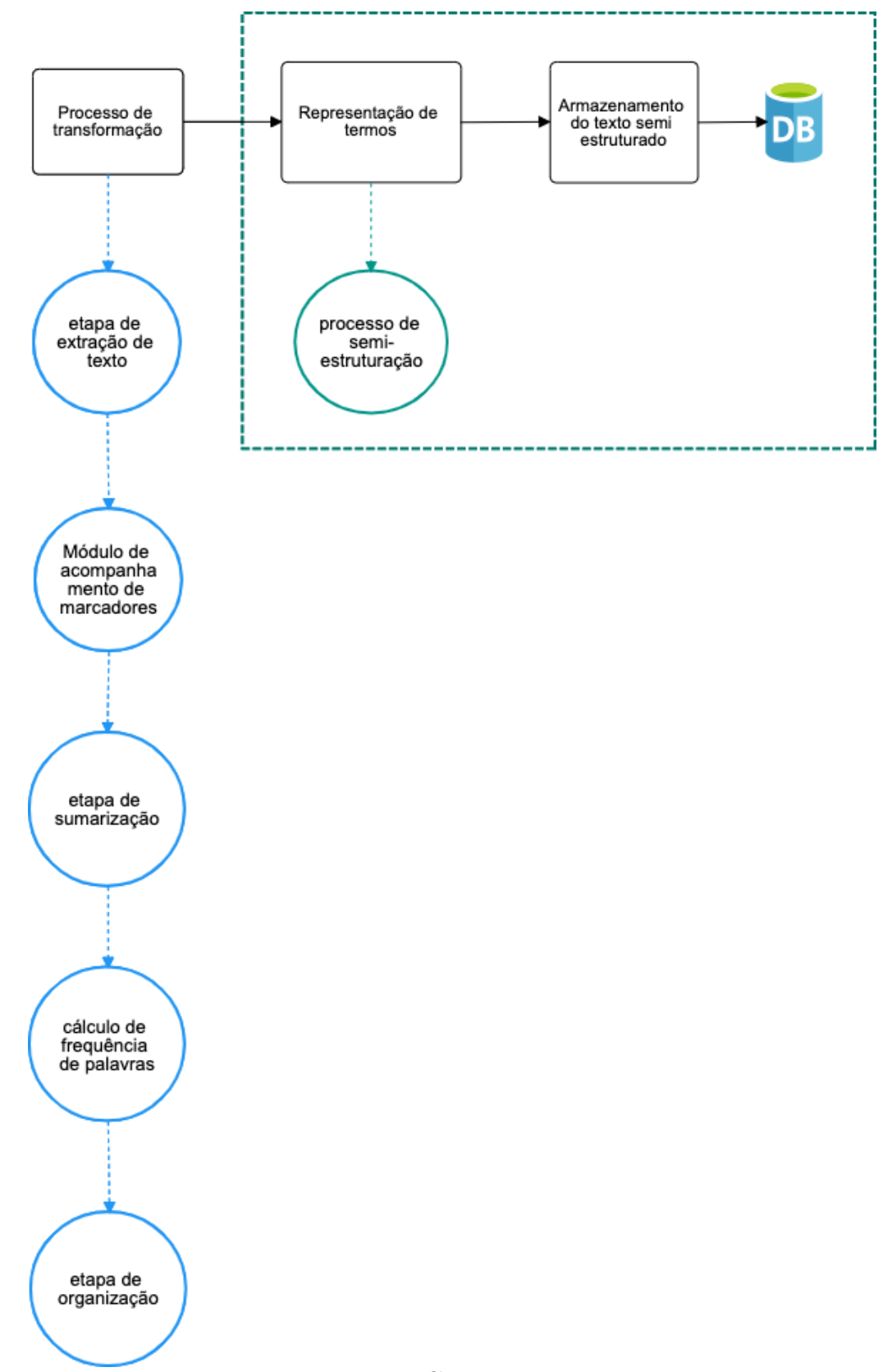

Fonte: Bianca Canezim Letti, 2019

A etapa de semiestruturação das informações extraídas e sumarizadas é a responsável por acomodar os dados extraídos em um formato que posteriormente possa ser lido, transformando dados em informações relevantes.

A figura 14 representa a semiestruturação identificada nesse projeto de pesquisa. A arquitetura proposta conseguiu, por meio dos dados simulados, notar que as conversações entre médicos e equipe geralmente se subdividem (de forma dinâmica, ou seja, não presentes em todas as conversas) em 4 categorias, sendo elas: 
- Identificação do paciente e localização dentro do hospital.

- Descrição do estado atual do paciente, geralmente expresso por meio de doenças, sintomas, e estado.

- Descrição dos exames que foram realizados ou estão sendo realizados no presente momento.

- Agendamentos de exames futuros, sejam eles de curto ou longo prazo, e também recomendações.

Figura 14 - Representação da semiestruturação da conversação

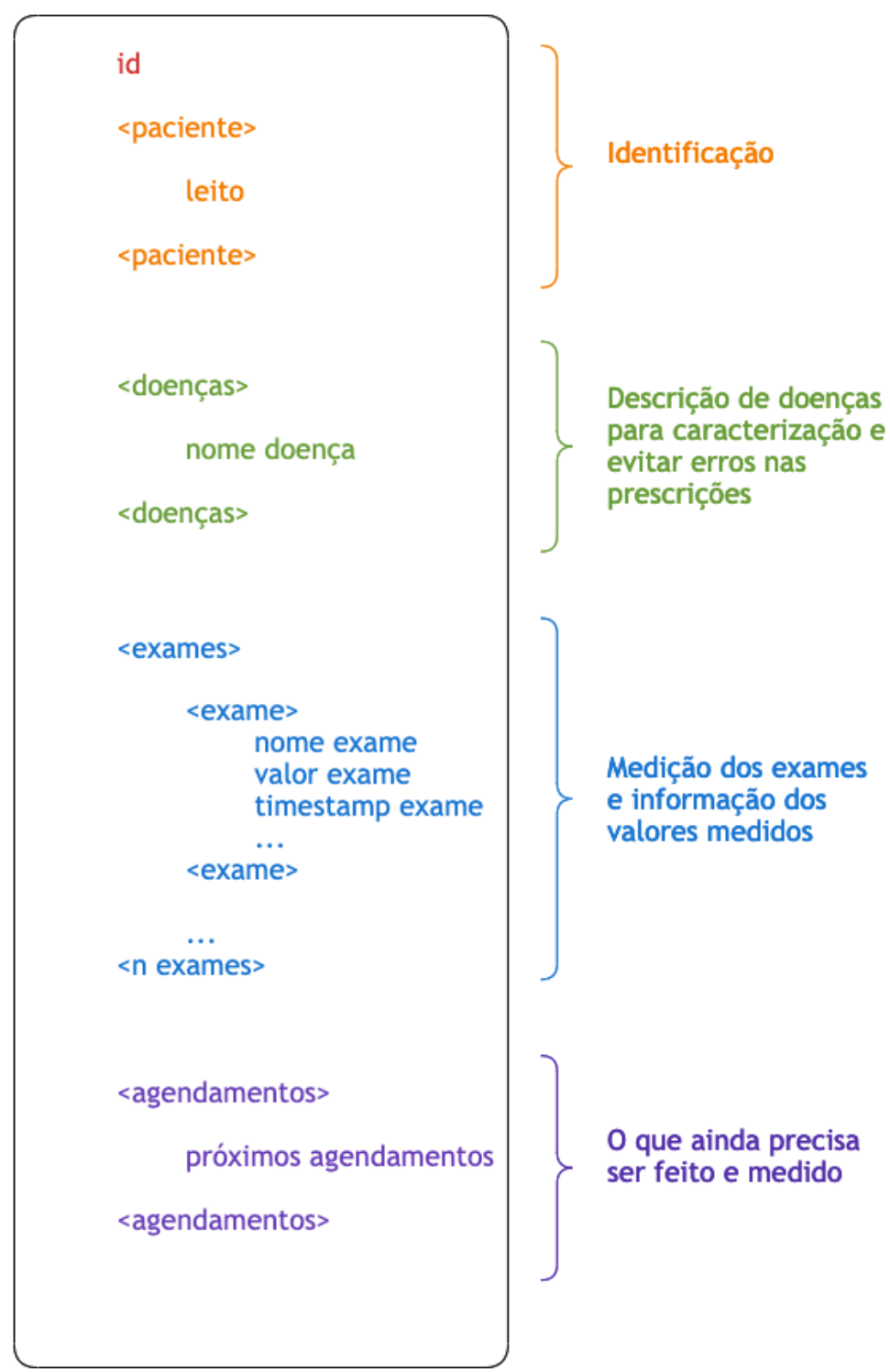

Fonte: Bianca Canezim Letti, 2019

Na figura, é possível verificar como foram organizados na abordagem proposta para essa arquitetura as quatro categorias identificadas. Uma observação importante é que não 
necessariamente a arquitetura está restrita a este formato de semiestruturação. Esse é um exemplo da semiestruturação dos dados, mas a arquitetura não é limitada a este modelo.

\subsection{Processo de Apresentação e Aprendizado}

A etapa de apresentação e aprendizado é a etapa que corresponde à camada de saída da arquitetura, portanto, essa é a etapa responsável por oferecer recursos para visualização dos termos acompanhados.

Nessa etapa, a arquitetura permite a inclusão de ferramentas de inteligência artificial e aprendizado de máquina para realizarem a tarefa de identificação e sugestão de termos a serem acompanhados.

Além da parte de aprendizado, esse processo é também responsável por realizar a preparação e estruturação da apresentação para a camada de saída. Ou seja, essa etapa oferece os recursos de recuperação dos dados referentes aos termos monitorados para que os mesmos possam ser visualizados. 


\section{Validação}

Este trabalho propôs uma arquitetura para representar e apoiar a comunicação entre médicos e equipe médica. Para validar essa arquitetura, foi realizada a implementação de um aplicativo de troca de mensagens instantâneas baseado na arquitetura proposta para assim permitir a realização de testes e simulações.

Essa implementação consistiu no desenvolvimento de um aplicativo chamado de healthMessage, API's que apoiaram na comunicação do frontend do aplicativo com o servidor e seus respectivos algoritmos de pré-processamento, implementação do módulo de acompanhamento de marcadores, cálculo de frequência de palavras, chamadas a um serviço terceiro de mensageria e implementações do banco de dados.

A validação também contou com o uso de dados simulados, fornecidos por uma equipe médica da Universidade Federal de Goiás. O conjunto de dados recebido consistia em simulações de troca de mensagens instantâneas, entre médicos, para o acompanhamento de pacientes.

Um exemplo do conjunto de dados pode ser analisado por meio do quadro 1 . No quadro é possível verificar, por meio das mensagens, como médicos se comunicam nos aplicativos de mensageria.

A análise do conjunto de conversas simuladas ressaltou a característica não estruturada das conversas. Também mostrou que parte do conteúdo é relacionado ao tratamento do paciente, como informações sobre acompanhamento, evolução do caso e comunicação de resultados de exames. Outra característica observada é a presença de informações recorrentes, como identificação do paciente ou número do seu leito, estado atual do paciente, medicamentos em uso, exames a serem realizados e previsões de próximas ações a serem feitas. Tais informações podem ser observadas em diferentes mensagens e, portanto, acompanhá-las exige a verificação de várias mensagens. 
Quadro 1 - Exemplo de dados simulados conversados entre médicos em aplicativos de mensageria instantânea

\begin{tabular}{|c|c|}
\hline Médicos & Pedaços de conversação simulada \\
\hline Médico 1 & $\begin{array}{l}\text { Leito 5: Paciente 12, } 65 \text { anos, adm: 18/01. CH/OH, Ascite re- } \\
\text { fratária, SDHR. Está com Nora baixa dose. Checar se realmente } \\
\text { tem nível de consciência para dieta oral. Fez paracentese e repôs } \\
\text { plasma, acordado porém lentificado, se estiver acordado, alta } \\
\text { com lactulose, metronidazol } 500 \mathrm{MG} \text { de } 8 / 8 \mathrm{H} \text {, sem diurético e } \\
\text { programar paracentese de 10/10 doas CD: sem exames }\end{array}$ \\
\hline Médico 3 & Leito 3 VAGO \\
\hline Médico 14 & $\begin{array}{l}\text { No leito } 1 \text { tem o Paciente x. Alcoolista, pancreatite }+ \text { hepatite } \\
\text { alcoólica. Está com crise convulsiva e sepse (foco pulmonar - } \\
\text { ainda com secreção purulenta). Fez febre na segunda (cateter? } \\
\text { pulmão?). O CDL foi trocado em 04/01. Em parâmetros mínimos } \\
\text { de vm... no entanto, não conseguimos extubar devido agitação. } \\
\text { Exames: gaso/NA/K/ Solicito TQT. }\end{array}$ \\
\hline
\end{tabular}

\subsection{Módulo da arquitetura de entrada e saída}

O healthMessage desenvolvido nessa pesquisa oferece as funcionalidades de mensageria necessárias para as atividades de comunicação da equipe de saúde no seu dia a dia de trabalho.

Para ilustrar a funcionalidade proposta nos módulos do healthMessage, a figura 15 ilustra o processo de entrada e saída realizados através do aplicativo, pela troca de mensagens para visualização de dados do paciente.

As etapas do processo estão descritas abaixo:

1. O médico inicia uma conversa (com outro médico ou equipe de saúde).

2. O médico adiciona marcadores na conversa.

3. As mensagens são enviadas para o módulo de processamento de mensagem, que, por sua vez, será o responsável por realizar as etapas de pré-processamento: extrair, acompanhar marcadores, sumarizar, calcular a frequência de palavras e organizar e por fim, também semiestruturar e armazenar as mensagens semiestruturadas.

4. O usuário ao acessar determinada seção do healthMessage que requer os dados semiestruturados, a camada de visualização prepara a exibição destes dados e exibe de forma organizada. 
Figura 15 - Diagrama de uso da troca de mensagens entre médico e o sistema e a etapa final de visualização dos dados do paciente de forma organizada.

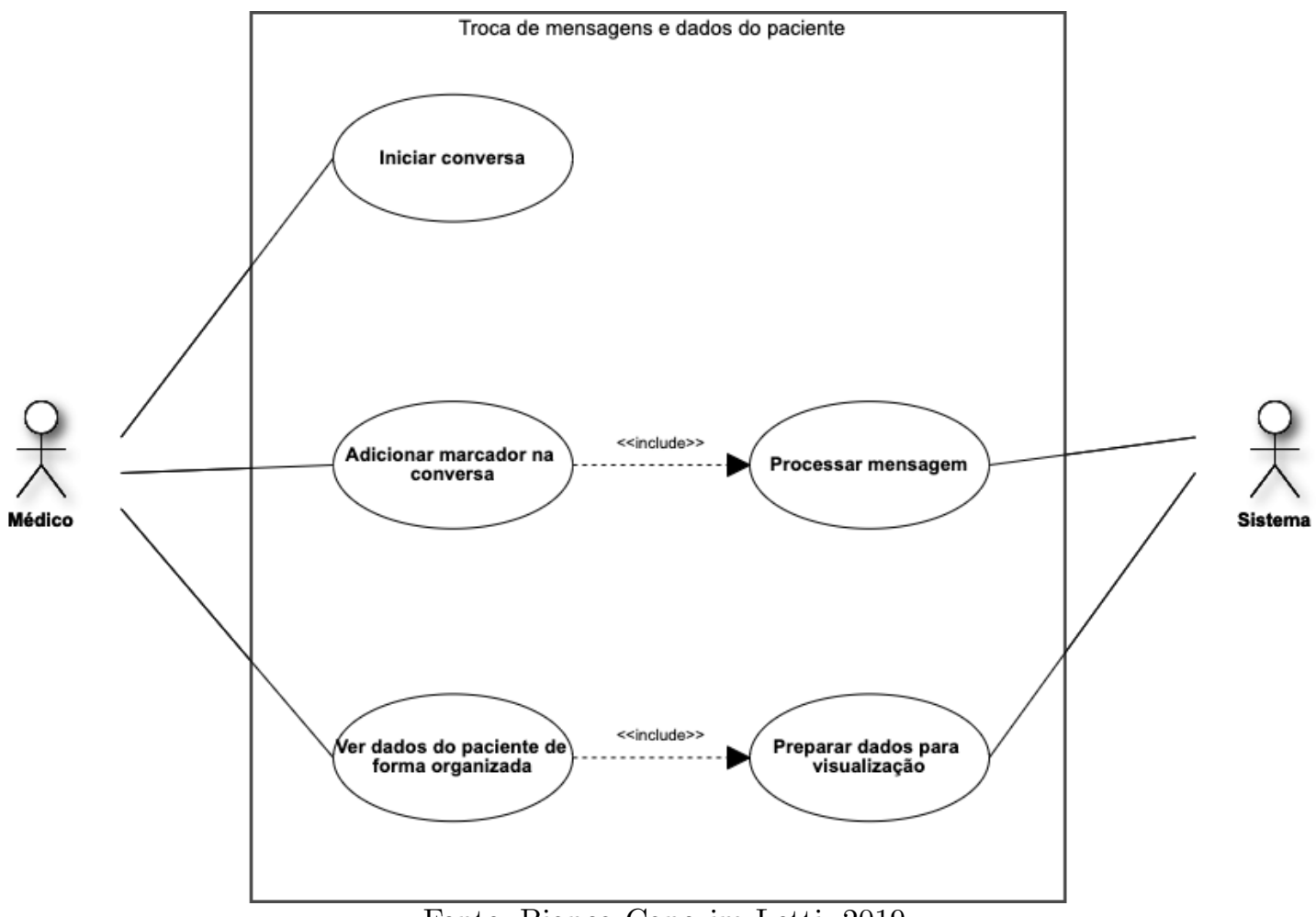

Fonte: Bianca Canezim Letti, 2019

A figura 16 apresenta a interface inicial do aplicativo, com a qual é controlado o acesso aos dados sensíveis protegidos por uma autenticação. 
Figura 16 - Validação arquitetura de entrada e saída - Login

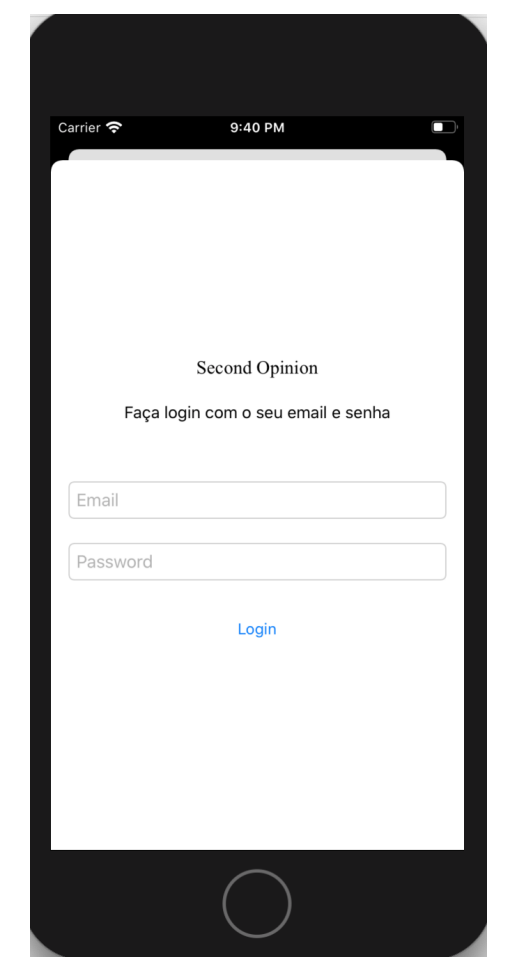

Fonte: Bianca Canezim Letti, 2019

A aplicação reconhece conversas entre vários usuários e entre várias equipes. A figura 17 mostra a interface de criação de grupos e conversas.

Figura 17 - Validação arquitetura de entrada e saída - Médicos

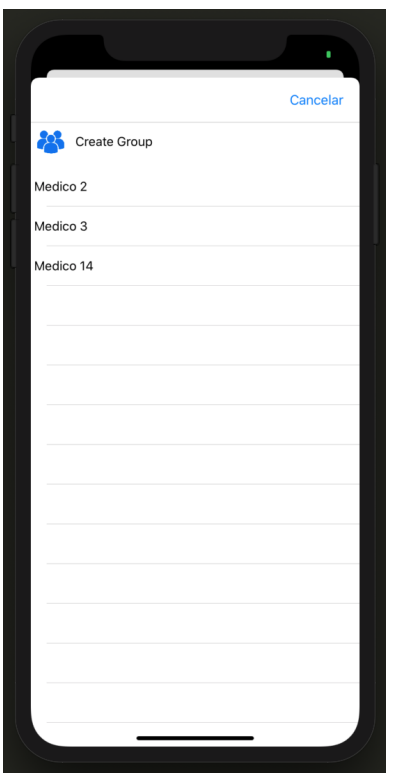

Fonte: Bianca Canezim Letti, 2019

Para validação, foram utilizados grupos ou conversações individuais entre médicos, baseados nos exemplos de conversas simuladas obtidas. O aplicativo oferece as funcionali- 
dades presentes em aplicativos de mensagens instanâneas. Nesse sentido, as conversações ficam disponíveis e podem ser acessadas com o uso da aba de navegação denominada "conversas". A figura 18 apresenta a lista de conversas tanto entre grupos como membros da equipe.

Figura 18 - Validação arquitetura de entrada e saída - Chats

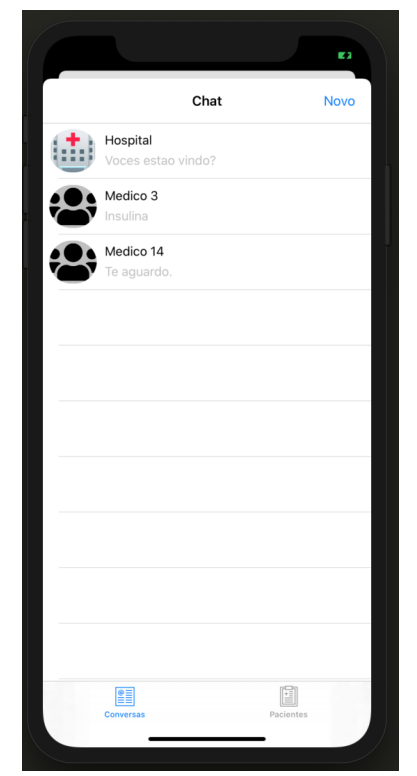

Fonte: Bianca Canezim Letti, 2019

Na figura 19 é apresentada a interação entre médicos. Na conversação apresentada, o médico 1 , representado pelo smartphone da esquerda, conversa com o médico 3 , representado pelo pelo smartphone da direita. Durante o diálogo, os médicos utilizam os marcadores de identificação, doenças e exames. Esse exemplo apresenta uma conversa na qual são visualizados o estado clínico, diagnóstico, medicamento em uso e valor de um exame realizado. O exame é a medição do valor da insulina. 
Figura 19 - Interação entre médicos com dados simulados no healthMessage - Parte 1

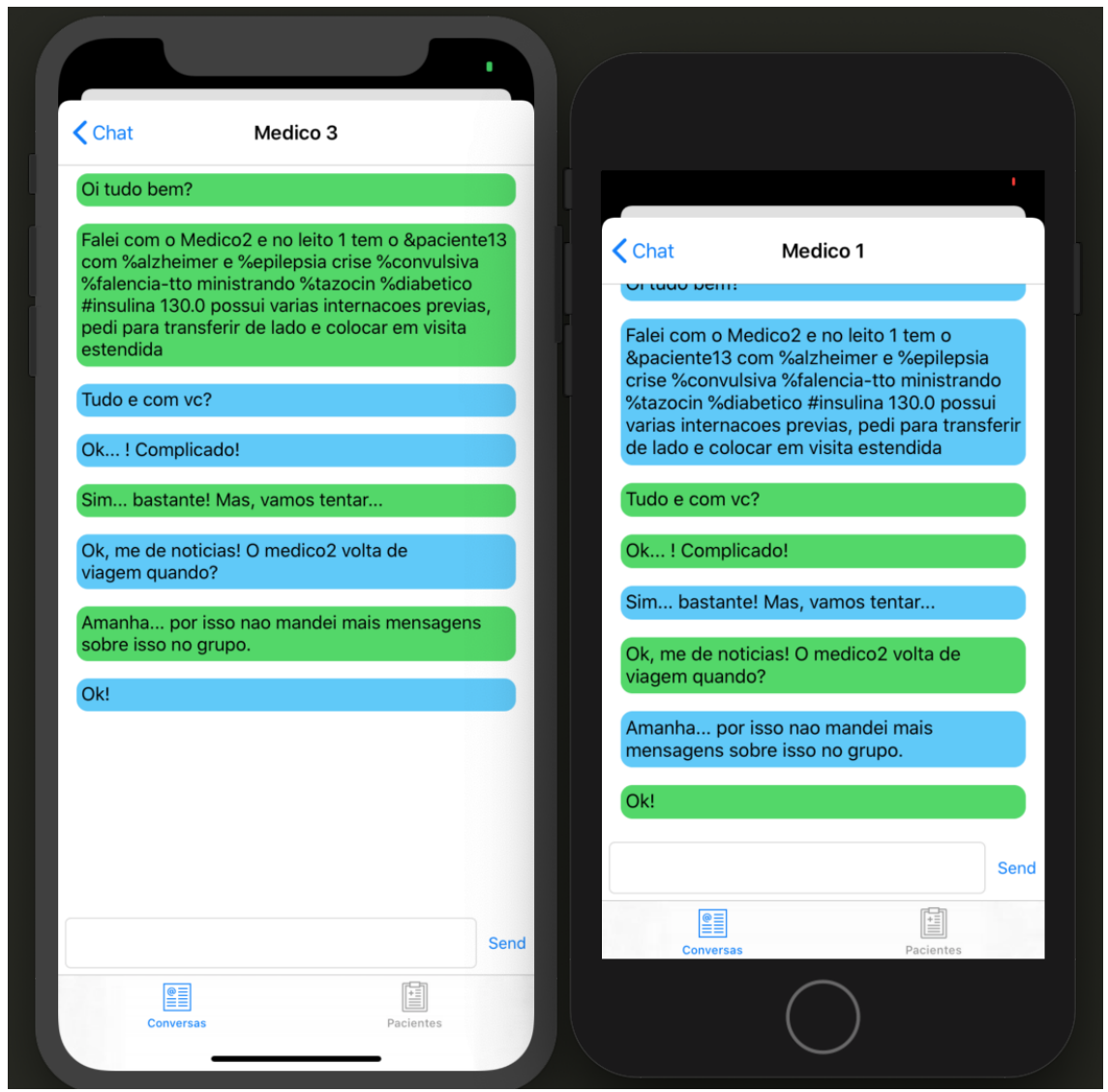

Fonte: Bianca Canezim Letti, 2019

As conversas ocorrem ao longo do dia e as necessidades dos pacientes mudam de acordo com o quadro clínico e da evolução do tratamento. Nesse sentido, novas informações sobre o estado do paciente, valores de exames, novos diagnósticos ou apenas informações de rotina podem ser trocadas entre a equipe de saúde. Na figura 20 é demonstrada a continuidade da troca de mensagens entre os dois médicos. Durante essa conversa, novos valores de insulina são informados. Esse cenário exemplifica como os valores de exames mudam e como frequentemente são compartilhados entre a equipe de saúde. 
Figura 20 - Interação entre médicos com dados simulados no healthMessage - Parte 2

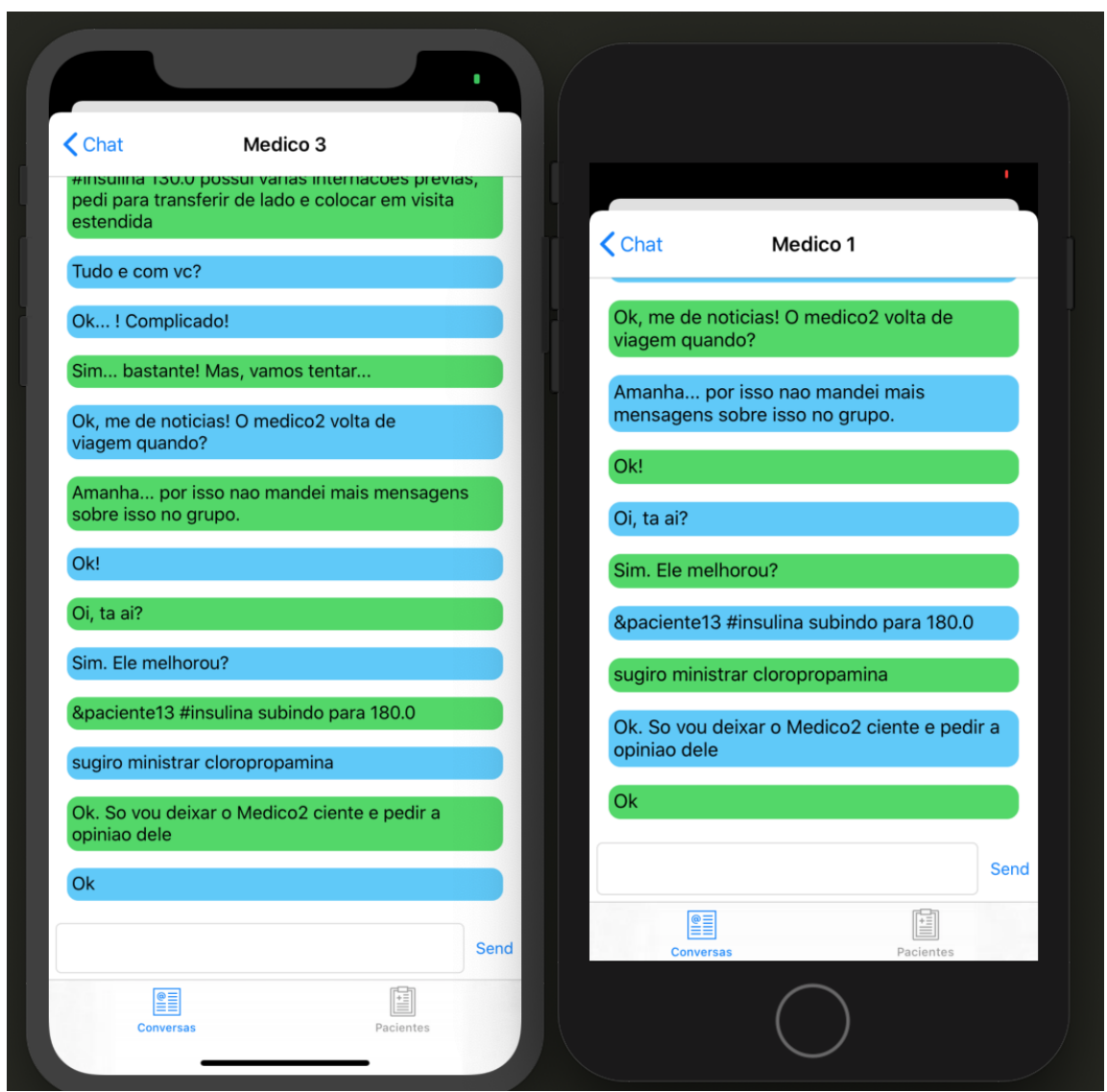

Fonte: Bianca Canezim Letti, 2019

Em continuidade à conversa, exames se repetem no quadro de cada paciente, de acordo com a doença ou tratamento realizado. Essa etapa está representada pela figura 21. Nela, mais um valor do exame de insulina é apresentado. Esses valores são agregados ao paciente para visualização na seção de pacientes, na qual é possível ver as informações de forma organizada. 
Figura 21 - Interação entre médicos com dados simulados no healthMessage - Parte 3

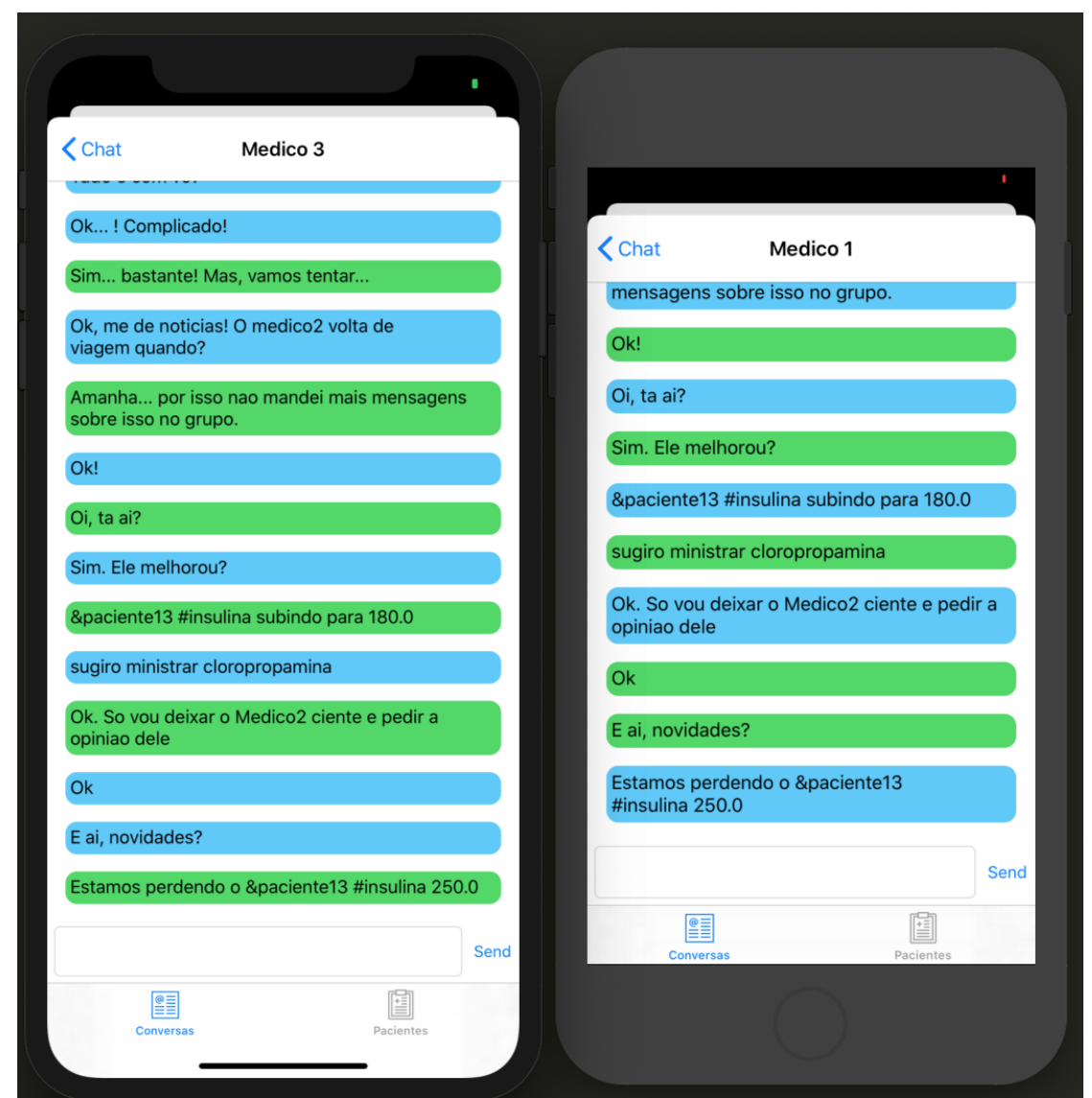

Fonte: Bianca Canezim Letti, 2019

\subsection{Módulo da arquitetura do servidor}

Para processamento das mensagens trocadas durante a comunicação entre as equipes, foi implementado a arquitetura proposta em módulo disponível em um servidor de aplicação.

O processo realizado no servidor está descrito abaixo:

1. Início do processamento

a) A etapa em que é utilizado o serviço terceiro para envio do texto e armazenamento do texto no formato de chat é iniciada.

b) Em paralelo, a etapa b é realizada para dar início ao processamento interno do algoritmo.

2. O serviço terceiro processa o texto recebido sem modificá-lo, em seu servidor interno.

3. O serviço terceiro armazena o texto recebido sem modificá-lo, para posterior recuperação do mesmo texto dentro da interface de chat. 
4. Após o algoritmo interno pré-processar, extrair, sumarizar, organizar e semiestruturar os dados, eles são armazenados em um banco de dados não relacional, orientado a documentos.

A imagem 22 ilustra esse processamento realizado no servidor, representado por um diagrama de gerenciamento de processo de negócio.

Figura 22 - Processamento no servidor

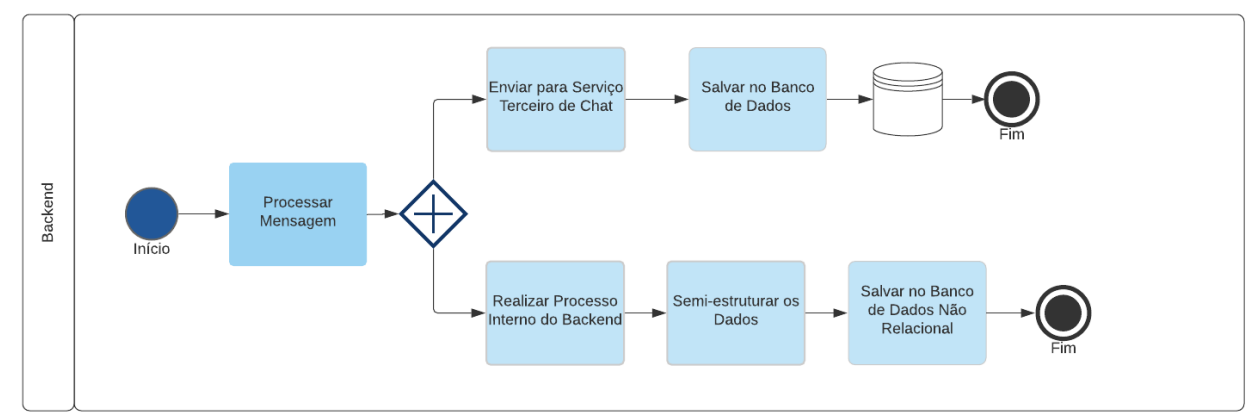

Fonte: Bianca Canezim Letti, 2019

Como ilustração da execução da $A P I$, que promove a comunicação das interfaces do healthMessage como os serviços fornecidos pelo módulo do servidor, a figura 23 apresenta um trecho de código utilizado para consumir a $A P I$.

Figura 23 - Demonstração de API node que realiza o envio de uma mensagem entre frontend e o servidor

api.post('/private_message', asyncMiddleware( async (req, res, next) $\Rightarrow\{$

let is $\mathrm{New}=$ req.query. is New

let message $=$ req. body $\cdot$ message

var result $=$ null;

if (req.body.recipient_id) \{

let recipientUserId $=$ req.body.recipient_id

let senderId $=$ req.body. sender_id

result = await chatService.sendMessageToUser(recipientUserId, senderId, message, isNew)

\} else \{

let dialogId $=$ req.body.chat_dialog_id

let senderId $=$ req.body. sender_id

\}

result = await chatService.sendMessageToDialog(dialogId, senderId, message)

console. $\log ($ result $)$

res.status(200).send(result)

\}))

Fonte: Bianca Canezim Letti, 2019

Os dados referentes aos termos monitorados foram armazenados em banco de dados não relacional, orientado a documentos. 
Figura 24 - Demonstração de trecho de código do servidor que é responsável pelo relacionamento com o banco de dados não relacional

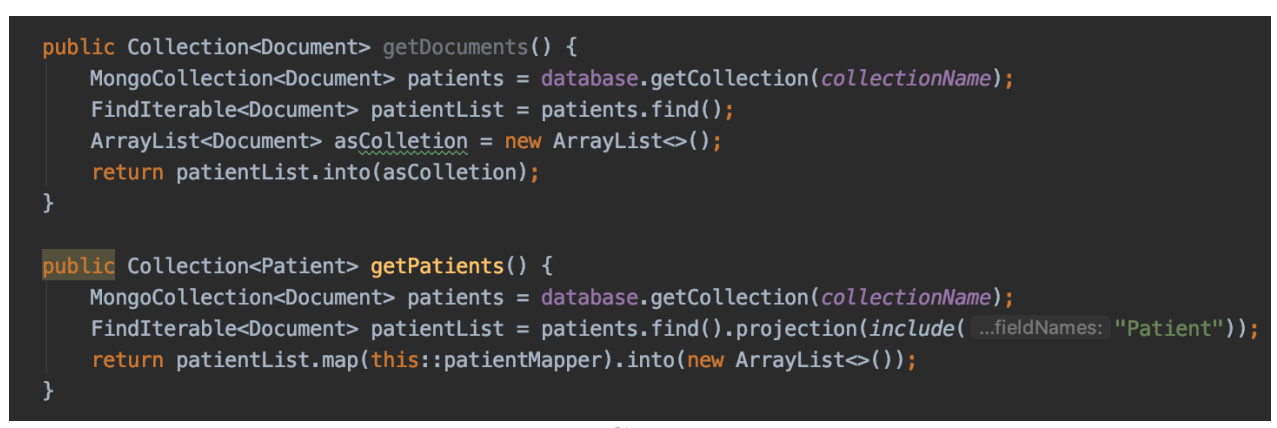

Fonte: Bianca Canezim Letti, 2019

\subsection{Módulo de transformação dos dados}

A etapa de processamento interno, realizada no servidor, é responsável pelo préprocessamento do texto, por meio da etapa de extração, acompanhamento de marcadores, sumarização e cálculo de frequência de palavras, fazendo transformações no texto para prepará-lo para o processo de semiestruturação.

Essas etapas desse processo estão representadas pela figura 25.

Figura 25 - Fluxograma de processo linear que representa o processamento de transformação dentro do servidor

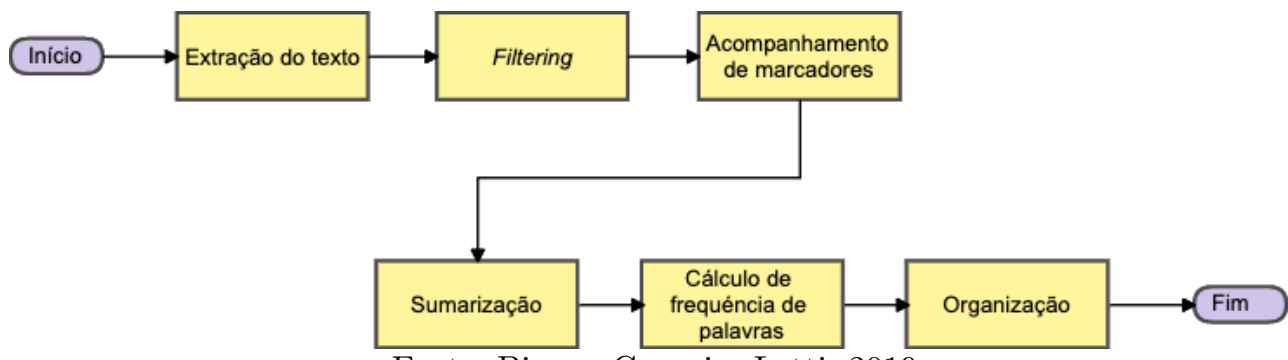

Fonte: Bianca Canezim Letti, 2019

As etapas realizadas são:

1. O processo é iniciado com o recebimento de uma mensagem.

2. O servidor realiza a extração das informações.

3. A pontuação é removida (filtering) no algoritmo por meio de expressões regulares.

4. O módulo de acompanhamento de marcadores realiza a identificação das informações relevantes.

5. A sumarização do texto é realizada com base nas informações relevantes.

6. A frequência de palavras é calculada com o apoio do algoritmo (MOL, 2016). 
7. A organização para envio dos dados semiestruturados é realizada.

\subsubsection{Frequência de Palavras}

A palavra insulina, conforme exemplo utilizado no contexto apresentado na seção de validação, possui alta relevância de acordo com o cálculo de frequência de utilização desse termo. Dessa forma, a figura 26 ilustra o processo de sugestão de palavras sugerindo a palavra insulina.

Figura 26 - Sugestão de palavras baseadas no cálculo de frequência de termos

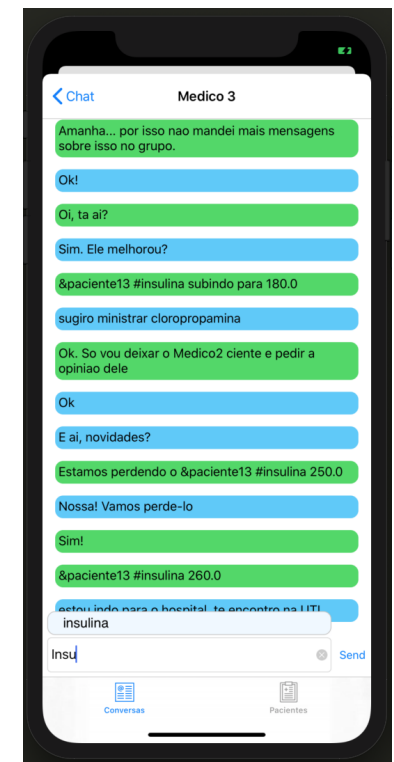

Fonte: Bianca Canezim Letti, 2019

7.3.2 Módulo de semiestruturação e organização

O processo realizado pelo servidor para semiestruturação e organização pode ser representado pelos passos abaixo:

1. Quando o usuário deseja acessar as informações de forma organizada no healthMessage (interface de saída), ele realiza a ação no aplicativo.

2. A requisição realizada pelo usuário é recebida pelo aplicativo e processada.

3. Uma $A P I$ recupera os dados semiestruturados, já organizados e armazenados no banco orientado a documentos.

4. A camada de apresentação recebe os dados semiestruturados.

5. A camada de apresentação mostra para o usuário os dados de forma organizada. 
Para essa pesquisa, como formato dos dados semiestruturados e organizados, foi escolhida a representação por $j S O N$, no entanto, a arquitetura é flexível e reconhece que múltiplos formatos sejam realizados para essa etapa.

A figura 27 é um exemplo do $j S O N$ de saída com os dados de conversação usados em contexto simulado.

Figura 27 - Representação da semiestruturação da conversação - jSON de saída

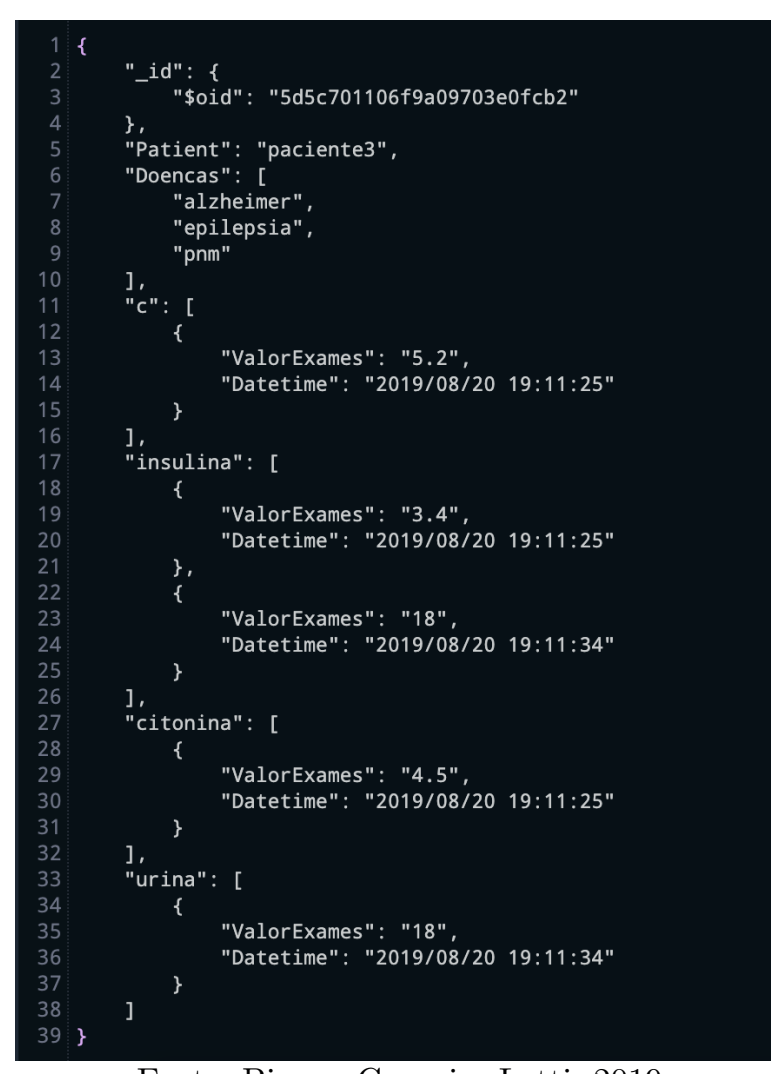

Fonte: Bianca Canezim Letti, 2019

7.3.3 Módulo de saída (visualização das informações organizadas)

Quando o médico acessa as informações do paciente, o processo da etapa de saída ocorre e está representado na figura 28. 
Figura 28 - Processamento de visualização das informações organizadas

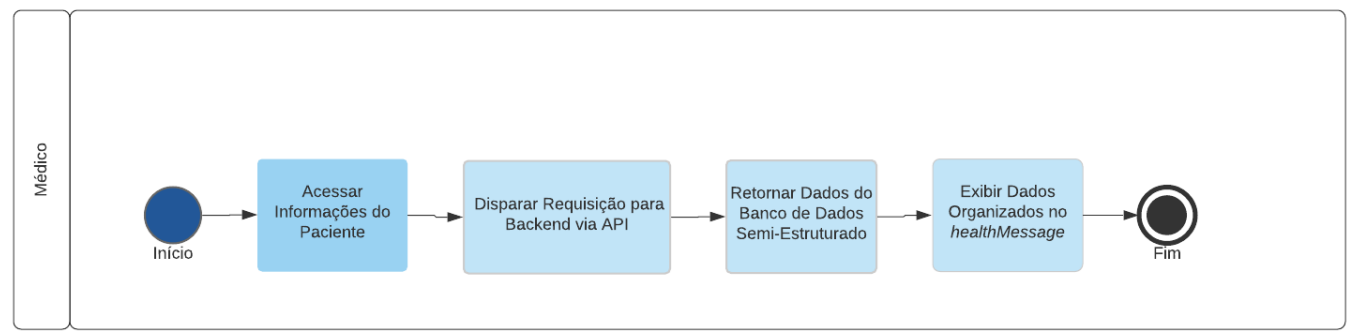

Fonte: Bianca Canezim Letti, 2019

Com base nos dados das conversações das imagens anteriores 19, 20 e 21, o resultado do processo de semiestruturação e organização são apresentados para o usuário final. A figura 29 mostra essa etapa. Nesta imagem é possível ver os valores de forma organizada, conforme foram conversados no chat e o timestamp em que foram conversados, além de ser possível acompanhar a evolução desses valores, facilitando a indicação visual para os médicos.

Figura 29 - Representação do processo de saída do contexto simulado após semiestruturação e organização

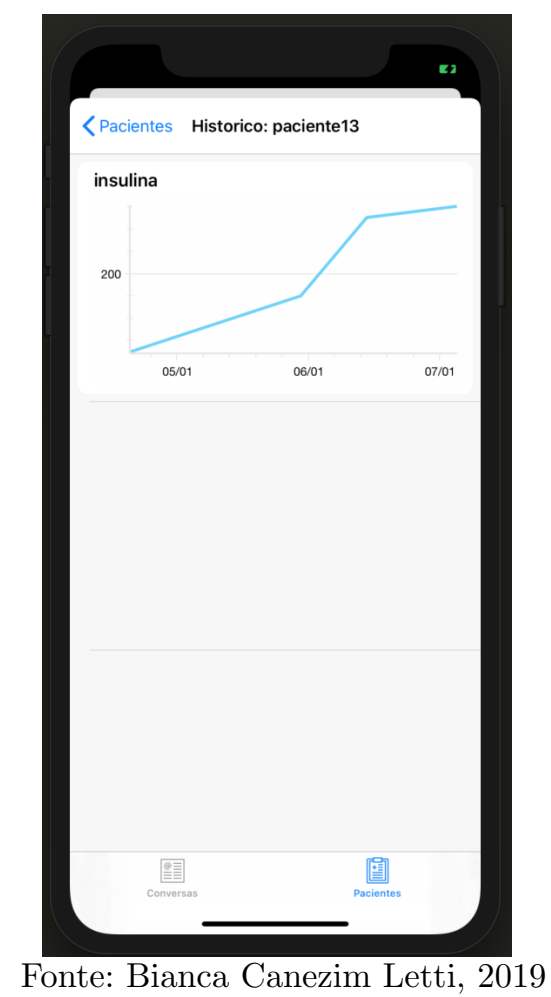

Outros exames (exames de sangue) em contexto simulado foram representados na figura para mostrar possíveis variações de exames e valores. 
Figura 30 - Representação do processo de saída do contexto simulado após semiestruturação e organização - Outros exames (exames de sangue)

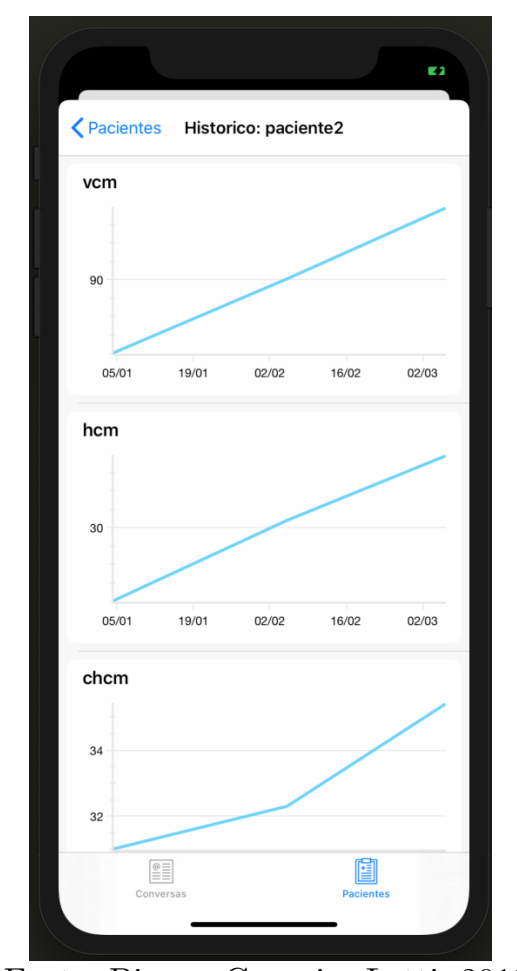

Fonte: Bianca Canezim Letti, 2019 


\section{Discussão}

Diante do impacto do uso dos smartphones na área da saúde para realização de atividades médicas diárias, principalmente em relação a tarefas de comunicação entre equipes e para obtenção de uma segunda opinião médica, com o uso de aplicativos de mensageria instantânea que, por sua vez, não foram criados para a atender às necessidades de comunicação na área da saúde e, portanto, conforme relatado na literatura avaliada por esse projeto, não oferecem recursos para otimizar a comunicação e auxiliar na prevenção de falhas de comunicação. Esse cenário apontou para a necessidade do surgimento de ferramentas que ofereçam segurança e facilidade de acompanhamento dos casos, para que informações importantes não sejam ignoradas e sejam consideradas no momento devido pelos responsáveis pelas condutas envolvidas no cuidado e tratamento do paciente.

A avaliação da forma e estrutura da comunicação entre as equipes de saúde permitiu identificar características que distinguem essa comunicação de outras realizadas em nosso contexto do cotidiano. Cada equipe desenvolve uma forma de comunicar própria com o uso de abreviaturas e símbolos para troca ágil das informações necessárias. Ou seja, nomes longos de medicamentos, exames e diagnósticos são substituídos por suas iniciais ou apelidos adotados pela equipe. Dessa forma, abordagens comumente usadas no processamento de texto com a remoção de stop words e a redução de uma palavra ao seu radical - stemming não são adequadas nesse contexto, por removerem ou agregarem palavras com relevante importância no contexto das mensagem de saúde. Tais características, em conjunto com a necessidade de acompanhamento da evolução do quadro clínico do paciente, e das atividades relacionadas ao tratamento, reforçam a contribuição de abordagens como a proposta neste trabalho.

A proposição de uma arquitetura modular traz a facilidade de evolução do ambiente para processamento de mensagens e proporcionou visitar as necessidades de comunicação com a solução em um ambiente integrado, com possibilidade de evolução para troca de algoritmos e tecnologias. Além disso, também traz a possibilidade de sua utilização para expansão de funcionalidades de aplicativos de mensageria existentes. A popularidade desses aplicativos indica uma tendência de crescimento de seu uso e esse trabalho apresenta funcionalidades que auxiliam na especialização de seus recursos para uma área de atuação específica. Também foi possível avaliar que a criação de um aplicativo próprio é factível. 
O aplicativo healthMessage possui as funcionalidades necessárias e pode ser ampliado para atender futuras demandas de comunicação. O desenvolvimento do aplicativo também apresenta como contribuição uma abordagem simplificada, para acompanhamento das mensagens com o uso de resumos das informações importantes e painéis de controle com gráficos de evolução das informações.

Com a validação realizada foi possível identificar, dentro do contexto de comunicação de equipes de saúde, elementos que fossem importantes para o tratamento dos pacientes, sejam eles fundamentais para o diagnóstico ou para o monitoramento do tratamento do paciente. Também foi possível extrair essas informações, sem que os médicos precisem procurá-las entre diversas mensagens trocadas, lembrar ou copiar e colar as mensagens anteriores, como normalmente é feito nas aplicações atualmente utilizadas pelas equipes de saúde. Essa simplificação do acesso à informação, não só agiliza a comunicação, como também pode contribuir para reduzir as falhas de comunicação e consequentes erros no tratamento do paciente.

A proposição de marcadores para identificação dos pacientes, suas doenças, diagnósticos e resultados de exames proporciona que a aplicação forneça recursos para acompanhamento do paciente e seu tratamento com o aproveitamento da cultura e forma de comunicar da equipe. Ou seja, uma mesma doença pode ser referenciada de formas distintas por equipes diferentes e mesmo assim serem acompanhadas. Apelidos, abreviaturas e outros padrões adotados pelas equipes podem continuar a ser utilizados. Essa abordagem aproveita o treinamento prévio da equipe e reduz as barreiras de adoção das funcionalidades propostas. Somado a isso, os marcadores permitem o uso imediato dos padrões de mensagem da equipe, sem que seja necessário o acúmulo de dados sobre as mensagens trocadas para a realização do treinamento de algoritmos de aprendizado, para só então iniciar a identificação dos padrões usados por cada equipe. Dessa forma, tanto os usuários ganham tempo com o uso imediato do aplicativo, quanto os algoritmos de aprendizado que passam a contar com o uso imediato e sem limitações para coletar os dados necessários para a realização de suas análises e contribuições. Os marcadores representam uma abordagem alternativa para apoiar a estruturação de mensagens sem a imposição de um formato ou padrão para representação das mensagens. Ou seja, o uso de marcadores em textos de mensagens pode ser expandido para fornecer novas funcionalidades e auxiliar no acompanhamento da comunicação. 
Por fim, os resultados deste trabalho atenderam a hipótese de que é possível organizar o conteúdo presente em mensagens trocadas de forma não estruturada para apoiar a comunicação entre equipes de saúde.

Este trabalho produziu o artigo de título: Data Representation and Processing Architecture to support healthcare team management submetido ao congresso, qualis B1, 33rd International Symposium on Computer Based Medical Systems (CBMS), IEEE.

\subsection{Trabalhos futuros}

Este projeto é a fase inicial da proposição de uma arquitetura que permite abordagens futuras e abre espaço para implementações e novas validações, fazendo parte de um projeto de pesquisa de escopo maior. Como próximos passos as tarefas a serem realizadas são: (1) implementar uma camada de aprendizado para que os marcadores sejam necessários nas fases iniciais de conversações entre médicos e equipes, (2) incluir tesauros médicos para auxiliar na classificação das palavras e auxiliar na sugestão e complementação de palavras durante a conversação e (3) realizar uma validação em um ambiente hospitalar incluindo testes para validar a usabilidade e adoção. 


\section{Conclusão}

O desenvolvimento do presente estudo possibilitou a construção de uma arquitetura capaz de apoiar a organização e gestão da informação para médicos e equipes de saúde, a fim de auxiliar na comunicação e na segunda opinião médica, durante a tomada de decisões e no tratamento de pacientes.

Os principais desafios enfrentados foram: (1) extrair informações de uma conversação que é caracterizada por dados não estruturados, (2) processar esses elementos, (3) transformar esses elementos em dados semiestruturados e (4) organizar as informações para contribuir com os médicos e equipes de saúde.

A primeira contribuição deste trabalho foi auxiliar o processo de comunicação entre médicos e equipe de saúde extraindo informações relevantes durante a conversação. Essa contribuição pode auxiliar a reduzir erros causados por falhas de comunicação. Além de promover uma rápida visualização de informações importantes trocadas durante as conversações.

A segunda contribuição foi a proposição de uma arquitetura modular para processamento de mensagens instantâneas. Essa arquitetura possibilita organizar e analisar as mensagens trocadas e assim oferecer um recurso extra para apoiar a comunicação. Ela auxilia na adaptação dos aplicativos de mensageria ao contexto de comunicação de uma equipe de saúde.

Por fim, a última contribuição foi organizar os dados, ajudando os médicos a fazer a gestão da informação, exames, diagnósticos, a fim de contribuir também com o processo de tomada de decisão e segunda opinião médica para melhorar a qualidade do tratamento dado ao paciente. 


\section{Referências $^{1}$}

AAMIR, M.; BHUSRY, M. Building recommendation system for hotel. International Journal of Computer Applications, v. 134, n. 9, p. 19-23, 2016. Citado na página 30.

ABDULLA, R. id. Second opinion. Pediatric Cardiology, Springer, v. 36, n. 2, p. 249-250, 2015. Citado na página 16.

AERONAUTICAL research: hearings before the subcommittee on advanced research and technology of the committee on science and astronautics, U.S. house of representatives, ninety-first congress, first session. 14. ed. [S.l.]: United States Congress House, 1969.

Citado na página 32.

ANSHARI, M.; ALMUNAWAR, M. N.; SHAHRILL, M.; WICAKSONO, D. K.; HUDA, M. Smartphones usage in the classrooms: Learning aid or interference? Education and Information Technologies, Springer Science Business Media New York, v. 22, n. 6, p. 3063-3079, 2017. Citado na página 15.

APPLE. Xcode 11. 2019. Disponível em: 〈https://developer.apple.com/xcode/whats-new/〉. Citado na página 32.

BALAKRISHNAN, V.; LLOYD-YEMOH, E. Stemming and lemmatization: A comparison of retrieval performances. Proceedings of SCEI Seoul Conferences, p. 174-179, 2014.

Citado na página 28.

BARIGOU, F.; ATMANI, B.; BELDJILALI, B. Using a cellular automaton to extract medical information from clinical reports. Journal of Information Processing Systems, KIPS, v. 8, n. 1, p. 67-84, 2012. Citado na página 26.

BEHERA, S.; KUMAR, N. Filtering of unstructured text. International Journal of Engineering Research and Development, IJERD, v. 11, n. 12, p. 45-49, 2015. Citado 3 vezes nas páginas 25,26 e 27.

BOUlOS, M. N. K.; BREWER, A. C.; KARIMKHANI, C.; BUllER, D. B.; DELLAVALLE, R. P. Mobile medical and health apps: State of the art, concerns, regulatory control and certification. Online Journal of Public Health Informatics, University of Illinois at Chicago Library, v. 5, n. 3, p. 229, 2014. Citado na página 15.

BOUlOS, M. N. K.; GIUSTINI, D. M.; WHEELER, S. Instagram and whatsapp in health and healthcare: An overview. Future Internet, Multidisciplinary Digital Publishing Institute, v. 8, n. 37, 2016. Citado 2 vezes nas páginas 17 e 36.

BUNEMAN, P. Semistructured data. In: Proceedings of the Sixteenth ACM SIGACT-SIGMOD-SIGART Symposium on Principles of Database Systems. New York, NY, USA: Association for Computing Machinery, 1997. (PODS '97), p. 117-121. ISBN 0897919106. Disponível em: 〈https://doi.org/10.1145/263661.263675〉. Citado na página 23.

CASTELlAnO, M.; MASTRONARDI, G.; APRILE, A.; TARRICONE, G. A web text mining flexible architecture. International Journal of Computer, Electrical, Automation,

1 De acordo com a Associação Brasileira de Normas Técnicas. NBR 6023. 
Control and Information Engineering, World Academy of Science, Engineering and Technology, v. 1, n. 8, p. 78-85, 2007. Citado na página 27.

CHEN, H.; NG, T. D.; MARTINEZ, J.; SCHATZ, B. R. A concept space approach to addressing the vocabulary problem in scientific information retrieval : An experiment on the worm community system. Journal of the american society for information science, John Wiley \& Sons, Inc., v. 48, n. 1, p. 17-31, 1997. Citado na página 30.

CHEN, P. P.-S. The entity-relationship model - toward a unified view of data. In: Readings in artificial intelligence and databases. [S.l.]: Elsevier, 1988. p. 98-111. Citado na página 23.

CLARK, J. Text Mining and Scholarly Publishing. [S.l.]: Publishing Research Consortium, 2013. Citado na página 26.

CODD, E. F. A relational model of data for large shared data banks. Communications of the ACM, ACM, v. 13, n. 6, p. 377-387, 1970. Citado na página 23.

CROCCO, G.; LOH, S. Agrupamento de textos por similaridade para sistema de clipping web: clusterclipping. Dissertação (Mestrado) — Universidade Luterana do Brasil, 2010. Citado na página 28.

CROFT, W. B.; METZLER, D.; STROHMAN, T. Search Engines Information Retrieval In Practice. [S.l.]: Pearson Education, 2009. Citado 3 vezes nas páginas 23, 25 e 26.

DAHL, R. Node.js. 2018. Disponível em: 〈https://nodejs.org/en/ 〉. Citado na página 32. FILHO, I. G. C. Classificação de texto projeto spam filter. 2016. Disponível em: 〈https://slideplayer.com.br/slide/3038696/〉. Citado 2 vezes nas páginas 9 e 29.

FILHO, I. G. C. Visual Studio. 2019. Disponível em: 〈https://visualstudio.microsoft.com/ pt-br/ $\rangle$. Citado na página 32.

FREE, C.; PHILlIPS, G.; WATSON, L.; GALLI, L.; FELIX, L.; EDWARDS, P.; PATEL, V.; HAINES, A. The effectiveness of mobile-health technologies to improve health care service delivery processes: A systematic review and meta-analysis. PLoS Med, PubMed, v. 10, n. 1, p. e1001363, 2013. Citado na página 15.

GIORDANO, V.; KOCH, H.; GODOY-SANTOS, A.; BELANGERO, W. D.; PIRES, R. E. S.; LABRONICI, P. Whatsapp messenger as an adjunctive tool for telemedicine: An overview. Interactive Journal of Medical Research, JMIR Publications, v. 6(2), n. 11, 2017. Citado 2 vezes nas páginas 17 e 36.

GSMA. The Mobile Economy 2020. 2020. Disponível em: 〈https://www.gsma.com/ mobileeconomy/wp-content/uploads/2020/03/GSMA_MobileEconomy2020_Global.pdf $\rangle$. Citado na página 15.

GULACTI, U.; LOK, U.; HATIPOGLU, S.; POLAT, H. An analysis of whatsapp usage for communication between consulting and emergency physicians. Journal of Medical Systems, Springer, v. 40, n. 6, p. 130, 2016. Citado na página 17.

HACK, A. F.; NUNES, L. F.; SILVA, M. H.; LIMA, T. T. F. de. Text Mining. 2013. Disponível em: 〈http://www.inf.ufsc.br/ luis.alvares/INE5644/G2_texto.pdf $\rangle$. Citado na página 28. 
HAN, J.; E, H.; LE, G.; DU, J. Survey on nosql database. In: IEEE. Pervasive computing and applications (ICPCA), 2011 6th international conference on. [S.1.], 2011. p. 363-366. Citado na página 24.

HAN, S.; YI, Y. J. How does the smartphone usage of college students affect academic performance? Journal of Computer Assisted Learning, John Wiley \& Sons, v. 35, n. 1, p. 13-22, 2018. Citado na página 15.

HEARST, M. What is text mining? SIMS, UC Berkeley, 2003. Citado na página 24.

HEERDEN, A. van; TOMLINSON, M.; SWARTZ, L. Point of care in your pocket: a research agenda for the field of m-health. Bull World Health Organ, v. 90, n. 5, p. 393-394, 2012. Citado na página 16.

HONORATO, D. de F.; LEE, H. D.; MACHADO, R. B.; WU, F. C.; NETO, A. P. Utilização da indexação automática para auxílio à construção de uma base de dados para a extração de conhecimento aplicada à doenças pépticas. I Workshop de computação, v. 1, p. 1-9, 2004. Citado 3 vezes nas páginas 9, 29 e 30.

INC, M. MongoDB. 2018. Disponível em: 〈https://www.mongodb.com/ $\rangle$. Citado na página 32.

INGERSOLL, G. S.; MORTON, T. S.; FARRIS, A. L. Taming Text: how to find, organize and manipulate it. [S.l.]: Manning, 2013. Citado 2 vezes nas páginas 9 e 27.

J.JOHNSTON, M.; KING, D.; ARORA, S.; BEHAR, N.; ATHANASIOU, T.; SEVDALIS, N.; DARZI, A. Smartphones let surgeons know whatsapp: an analysis of communication in emergency surgical teams. The American Journal of Surgery, Elsevier, v. 209, n. 1, p. 45-51, 2015. Citado na página 17.

JUNIOR, J. R. C. Desenvolvimento de uma metodologia para Mineração de Textos. Dissertação (Mestrado) - Pontifícia Universidade Católica do Rio de Janeiro - PUC RIO, 2008. Citado na página 24.

KAY, R. Markup Languages. 2005. Disponível em: 〈https://www.computerworld.com/ article/2558597/markup-languages.html $\rangle$. Citado na página 22.

KENDIG, C. E. What is proof of concept research and how does it generate epistemic and ethical categories for future scientific practice? Science and Engineering Ethics, Springer, v. 22, p. 735-753, 2015. Citado na página 31.

KONTIO, M.; MARTTILA-KONTIO, M.; HOTTI, V. Data assessment model for strategic management. IBIMA Publishing, v. 2015, 2015. Citado 2 vezes nas páginas 22 e 23 .

KRUIZE, J. W. Advancement of farming by facilitating collaboration: Reference architecures and models for farm software ecosystems. [S.l.]: Wageningen University, 2017. Citado na página 32.

KUUS, O. Small-scale implementation of structured documentation - A case study of user experience and implementation approach. Tese (Doutorado) - Karolinska Institute, 2014. Citado na página 23. 
LADAGA, F. M. A.; ANDRADE, G. R. de; SARTORI, A. C.; YAMAGUCHI, M. U. Whatsapp uma ferramenta emergente para a promoção da saúde. Enciclopédia Biosfera, v. 15, n. 28, p. 1370-1384, 2018. Citado na página 18.

LANE, H.; HOWARD, C.; HAPKE, H. M. Natural Language Processing in Action: understanding, analyzing, and generating text with Python. [S.l.]: Manning, 2019. Citado na página 30.

LINDENBAUM, J.; WIGGINS, A.; HENR, O. Heroku. 2007. Disponível em: $\langle$ http://heroku.com/〉. Citado na página 32.

LOVINS, J. B. Development of a stemming algorithm. Mechanical Translation and Computational Linguistics,, v. 11, p. 22-31, 1968. Citado na página 28.

MAIER, D. The theory of relational databases. [S.l.]: Computer science press Rockville, 1983. v. 11. Citado na página 23.

MANUKYAN, M.; GEVORGYAN, G. Canonical data model for data warehouse. Communications in Computer and Information Science, Scopus, v. 637, p. 72-79, 2016. Citado na página 24.

MICROSOFT. Xamarin. 2011. Disponível em: 〈https://dotnet.microsoft.com/apps/ xamarin $\rangle$. Citado na página 32.

MOL, M. Rosetta Code. 2016. Disponível em: 〈http://www.rosettacode.org/wiki/ Rosetta_Code). Citado na página 57.

MORSCH, J. A. Segunda opinião médica: como funciona, importância, legislação e ética. 2019. Disponível em: 〈https://telemedicinamorsch.com.br/blog/segunda-opiniao-medica〉. Citado na página 16.

NADEAU, D.; SEKINE, S. A survey of named entity recognition and classification. Journal of Linguistic Investigations, v. 30, n. 1, p. 3-26, 2007. Citado na página 26.

NASCIMENTO, I. J. B. do; OLIVEIRA, J. A. de Q.; WOLF, I. S.; RIBEIRO, L. D.; SILVA, M. V. R. S. e; CARDOSO, C. S.; MARS, M.; RIBEIRO, A. L.; MARCOLINO, M. S. Use of smartphone-based instant messaging services in medical practice: a cross-sectional study. Sao Paulo Medical Journal, Scielo, v. 138, n. 1, p. 86-92, 2020. Citado 2 vezes nas páginas 18 e 19.

NENKOVA, A.; MCKEOWN, K. A survey of text summarization techniques. In: Mining Text Data. [S.l.]: Springer US, 2012. p. 43-76. Citado 2 vezes nas páginas 25 e 26.

ORACLE. Java. 2019. Disponível em: 〈https://www.java.com/pt_BR/〉. Citado na página 32 .

OULASVIRTA, A.; RATTENBURY, T.; MA, L.; RAITA, E. Habits make smartphone use more pervasive. Personal and Ubiquitous Computing, Springer-Verlag London, v. 16, n. 1, p. 105-114, 2011. Citado na página 15.

PADHY, R. P.; PATRA, M. R.; SATAPATHY, S. C. Rdbms to nosql: reviewing some next-generation non-relational database's. International Journal of Advanced Engineering Science and Technologies, v. 11, n. 1, p. 15-30, 2011. Citado na página 22. 
PARK, B.-W.; LEE, K. C. The effect of users' characteristics and experiential factors on the compulsive usage of the smartphone. International Conference on Ubiquitous Computing and Multimedia Applications, Springer Berlin Heidelberg, p. 438-446, 2011. Citado na página 15.

PAYNE, K. F. B.; WHARRAD, H.; WATTS, K. Smartphone and medical related app use among medical students and junior doctors in the united kingdom (uk): a regional survey. Medical Informatics and Decision Making, Biomed Central, v. 12, n. 121, 2012. Citado na página 16.

POIBEAU, T. Boosting robustness of a named entity recognizer. International Journal of Semantic Computing, World Scientific Publishing Company, v. 3, n. 1, p. 91-104, 2009. Citado na página 26.

QUICKBLOX. QuickBlox. 2018. Disponível em: 〈https://quickblox.com/〉. Citado na página 32 .

RANJAN, J. The 10 vs of big data framework in the context of 5 industry verticals. Productivity, v. 59, n. 4, p. 324-342, 2019. Citado 2 vezes nas páginas 22 e 23.

RUCHLIN, H. S.; FINKEL, M. L.; MCCARTHY, E. G. The efficacy of second-opinion consultation programs: A cost-benefit perspective. Medical Care, Lippincott-Raven Publishers, v. 20, n. 1, p. 3-20, 1982. Citado na página 16.

SAGAYAM, R.; S.SRINIVASAN; ROSHNI, S. A survey of text mining: Retrieval, extraction and indexing techniques. International Journal Of Computational Engineering Research, IJCER, v. 2, n. 5, p. 1443-1446, 2012. Citado na página 25.

S.KANNAN; GURUSAMY, V. Preprocessing techniques for text mining. Conference Paper, India, 2014. Citado 3 vezes nas páginas 27, 28 e 30.

SODERLAND, S. Learning information extraction rules for semi-structured and free text. Machine Learning, Kluwer Academic Publishers, v. 34, n. 1-3, p. 233-272, 1999. Citado na página 17.

SUBHI, Y.; BUBE, S. H.; BOJSEN, S. R.; THOMSEN, A. S. S.; KONGE, L. Expert involvement and adherence to medical evidence in medical mobile phone apps: A systematic review. JMIR Mhealth Uhealth, PubMed, v. 3, n. 3, p. e79, 2015. Citado na página 16.

S.VIJAYARANI; JANANI, R. Text mining: Open source tokenization tools - an analysis. Advanced Computational Intelligence: An International Journal, v. 3, n. 1, p. 37-47, 2016. Citado 3 vezes nas páginas 9, 24 e 25.

VERMA, T.; RENU; GAUR, D. Tokenization and filtering process in rapidminer. International Journal of Applied Information Systems (IJAIS), Foundation of Computer Science FCS,, v. 7, n. 2, p. 16-18, 2014. Citado na página 27.

VIJAYARANI, S.; ILAMATHI, J.; NITHYA. Preprocessing techniques for text mining-an overview. International Journal of Computer Science \& Communication Networks, v. 5, n. 1, p. 7-16, 2015. Citado 2 vezes nas páginas 24 e 29. 
WANI, S. A.; RABAH, S. M.; ALFADIL, S.; DEWANJEE, N.; NAJMI, Y. Efficacy of communication amongst staff members at plastic and reconstructive surgery section using smartphone and mobile whatsapp. Indian Journal of Plastic Surgery, Thieme Medical Publishers, v. 46, n. 3, p. 502-505, 2013. Citado na página 17.

WU, N.; GONG, E.; WANG, B.; GU, W.; DING, N.; ZHANG, Z.; CHEN, M.; YAN, L. L.; OLDENBURG, B.; XU, L.-Q. A smart and multifaceted mobile health system for delivering evidence-based secondary prevention of stroke in rural china: Design, development, and feasibility study. JMIR Mhealth Uhealth, PubMed, v. 7, n. 7, p. e13503, 2019. Citado na página 16.

YAHYA, H. Healthcare-related smartphone use among doctors in hospitals in kaduna, nigeria - a survey. Nigerian Journal of Clinical Practice, Nigerian Journal of Clinical Practice, v. 22, n. 7, p. 897-905, 2019. Citado na página 18. 